\title{
Potential and limitations of using soil mapping information to understand landscape hydrology
}

\author{
F. Terribile ${ }^{1}$, A. Coppola ${ }^{2}$, G. Langella ${ }^{1,4}$, M. Martina ${ }^{3}$, and A. Basile ${ }^{4}$ \\ ${ }^{1}$ Department of Soil, Plant, Environment and Animal Production Sciences, University of Napoli Federico II, \\ Portici, Napoli, Italy \\ ${ }^{2}$ Department for Agricultural and Forestry Systems Management, Hydraulic Division, University of Basilicata, Potenza, Italy \\ ${ }^{3}$ Department of Earth and Geo-Environmental Sciences, University of Bologna, Bologna, Italy \\ ${ }^{4}$ Institute for Mediterranean Agricultural and Forestry Systems, National Research Council, Ercolano, Napoli, Italy
}

Received: 31 March 2011 - Published in Hydrol. Earth Syst. Sci. Discuss.: 17 May 2011

Revised: 30 November 2011 - Accepted: 6 December 2011 - Published: 22 December 2011

\begin{abstract}
This paper addresses the following points: how can whole soil data from normally available soil mapping databases (both conventional and those integrated by digital soil mapping procedures) be usefully employed in hydrology? Answering this question requires a detailed knowledge of the quality and quantity of information embedded in and behind a soil map.

To this end a description of the process of drafting soil maps was prepared (which is included in Appendix A of this paper). Then a detailed screening of content and availability of soil maps and database was performed, with the objective of an analytical evaluation of the potential and the limitations of soil data obtained through soil surveys and soil mapping. Then we reclassified the soil features according to their direct, indirect or low hydrologic relevance. During this phase, we also included information regarding whether this data was obtained by qualitative, semi-quantitative or quantitative methods. The analysis was performed according to two main points of concern: (i) the hydrological interpretation of the soil data and (ii) the quality of the estimate or measurement of the soil feature.

The interaction between pedology and hydrology processes representation was developed through the following Italian case studies with different hydropedological inputs: (i) comparative land evaluation models, by means of an exhaustive itinerary from simple to complex modelling applications depending on soil data availability, (ii) mapping of
\end{abstract}

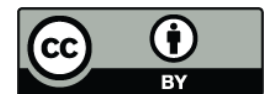

Correspondence to: $\mathrm{G}$. Langella (glangella@unina.it) soil hydrological behaviour for irrigation management at the district scale, where the main hydropedological input was the application of calibrated pedo-transfer functions and the $\mathrm{Hy}$ drological Function Unit concept, and (iii) flood event simulation in an ungauged basin, with the functional aggregation of different soil units for a simplified soil pattern.

In conclusion, we show that special care is required in handling data from soil databases if full potential is to be achieved. Further, all the case studies agree on the appropriate degree of complexity of the soil hydrological model to be applied. We also emphasise that effective interaction between pedology and hydrology to address landscape hydrology requires (i) greater awareness of the hydrological community about the type of soil information behind a soil map or a soil database, (ii) the development of a better quantitative framework by the pedological community for evaluating hydrological features, and (iii) quantitative information on soil spatial variability.

\section{Introduction}

\subsection{Hydropedology and landscape hydrology}

Soil plays a key role in hydrology since its importance in partitioning water between infiltration and runoff, storage, filtering, physical and chemical support to vegetation, etc. (Dunne, 1978). Soil scientists established a classification long time ago (Yaalon and Berkowicz, 1997). Similarly, there has been an increase of attention to quantitative taxonomy also in hydrology (McDonnell et al., 2007;

Published by Copernicus Publications on behalf of the European Geosciences Union. 
Wagener et al., 2007) especially to face predictions in ungauged basins, PUB, (http://eguleonardo2010.lippmann.lu/ objectives.php). To this respect soil classification and soil mapping can also play a role in reducing uncertainty in hydrological predictions especially when hydrological monitoring data are lacking (see general statements of this special issue).

In this paper we shall refer to the term "landscape hydrology" (also employed in other hydropedological studies such as Lin et al., 2006; Zhu et al., 2007) rather than the classical watershed hydrology or basic hydrology. This is because many soil hydrological and hydropedological studies/approaches employed in this paper deal with soils in the landscape, which do not necessarily match to actual watershed.

In recent years many advances have been attained by soil scientists in ameliorating soil information in both the estimate of hydrological parameters (e.g. by pedotransfer functions, PTFs, early defined by Bouma, 1989, as predictive functions of hydraulic properties from other more available, easily, routinely, or low costly measured properties as texture, organic carbon, structure, etc.) and the spatial inference of soil information (e.g. McBratney et al., 2003; Grunwald, 2009). In this regard, hydropedology (Bouma, 2006; Lin et al., 2006; Lin, 2011) has emerged as a new discipline devoted to the close interaction between soil science and hydrology, embracing multiscale process analysis in saturated and unsaturated soil conditions. This discipline promises to both enhance the understanding and prediction of rainfall-runoff processes (Lin et al., 2008) and to be a powerful tool for environmental policy research (Bouma, 2006).

Some evident examples of this potential are given in literature on the relationships between soil (soil architecture) and rainfall/runoff processes. Amongst others, Lin et al. (2008) analysed the contributions of hydropedology to the understanding and modelling of surface/subsurface runoff processes at microscopic (macropores and aggregates), mesoscopic (horizons and pedons) and macroscopic (hillslopes and catchments) scales; Bouma et al. (2008) showed the high potential of hydropedology in addressing end user multiscale land use problems; Bouma (1981) and Ritsema et al. (2005) related preferential flow paths to soil morphology and soil hydrophobicity, respectively; Coppola et al. (2009) studied the effects of a bimodal pore-size distribution and its variability on a hillslope water balance. In an attempt to conceptualize the relationships between hydrology and pedology, Lin et al. (2008) and Lin (2010) have (i) framed hydropedology in the more general domain of earth's critical zone; (ii) created a hierarchical framework for bridging soil type distribution (forms) and soil processes (functions) in hydropedology; (iii) emphasised soil structural complexity at different scales (aggregates, horizon, profile, catena, etc.); and (iv) defined the Hydrologic Functional Unit (HFU) as the soil-landscape mapping unit with similar pedologic and hydrologic functions (Lin et al., 2008). Despite these interesting conceptualizations, one basic point yet to be addressed by hydropedologists concerns if/how whole soil data from standard soil mapping databases (which is often the only available soil data) can be usefully employed by hydrologists. To answer this question we need detailed knowledge on the quality and quantity of information embedded in and behind a soil map.

\subsection{Soil mapping in the framework of landscape hydrology}

Before approaching the use of soil database in hydrology we indeed must report a preliminary synoptic view on soil mapping from a hydrological perspective. A more detailed description of this issue along with a glossary of basic soil science terms (useful for reading this paper) is provided in Appendix A and B.

Here we must start acknowledging (Dokuchaev, 1883; Jenny, 1941) that any soil (or soil property) is formed through the interaction of the following environmental (or soil forming) factors: climate, organisms, topography, parent material and time of soil formation (named CLORPT equation). Subsequently the analysis of these factors is indeed a strong help for understanding soils and soil behaviour.

This conceptual framework emphasises some important points for hydrologists: (i) if we aim to understand soils, soil (hydrologic) properties, soil functions and soil spatial distribution then we must adopt a robust multidisciplinary approach including the above environmental factors, (ii) as a consequence it is not possible to derive soil information from solely geological or vegetation data, (iii) in real landscape the spatial variability of climate, organisms, topography and parent material indeed forge the soil spatial variability. To this respect the above conceptual framework is very much aligned with some new paradigms looking to the hydrology of the future (McDonnel et al., 2007), more focused to discuss on the "why" the heterogeneity exists rather than the "which" heterogeneity exists.

Unfortunately this appealing conceptual framework, where soils and soils distribution are strongly related to the above environmental factors, has also a strong embedded weakness since it is a rather difficult task to know/estimate the state of these factors throughout the long time of soil formation at a specific landscape position.

Then it is not surprising that both conventional and digital soil mapping use the above soil forming factors as a very important support (e.g. soil covariates) for determining the soil spatial distribution rather than parameters to be incorporated in a mechanistic soil spatial distribution model.

A synoptic hydrological view of soil mapping must emphasise that the production of any soil map include different activities typically performed by different experts, somehow all coordinated by pedologists: (i) describing and sampling soils at specific landscape positions, usually soil profiles (typically performed by pedologists), (ii) performing 
chemical, physical and biological analysis on the sampled soils (respectively performed by soil chemists, soil hydrologists and soil biologists), (iii) classifying soils using international systems (such as WRB, 2006; USDA, 2010) on the base of both field and lab analysis, and (iv) producing a spatial distribution of either/both classified soil types and/or field and lab analysis into a coherent spatial framework as provided by a soil map in an analog form (typically performed by conventional pedologists) or digital form (typically performed by digital soil map experts, geostatisticians, etc.). Of course activity (iv) can indeed instruct activity (i) in locating soils to be described, sampled and then analysed.

The results from all these activities/expertise are then summarised in the final soil map and its corresponding soil database.

These soil maps, in the last century, have mainly relied on qualitative approaches (Soil Survey Division Staff, 1993; McKenzie et al., 2008), based on standardized survey methods, enabling to analyse and report the spatial distribution of soils (see Appendix A). These maps have been, and they are still, largely employed as indispensable tools for planning proper land management throughout the world (e.g. Stolpe et al., 1998; Herrero et al., 2007).

Nowadays, some limitations and drawbacks of these conventional soil maps have become apparent and as a result much advancement have been produced in mapping soils using more quantitative approaches. More specifically Digital Soil Mapping (DSM) has emerged as a credible alternative to traditional soil mapping. It entails the use of new tools and techniques coming from different branches of a broader scientific community (e.g. spatial statistics, GIS, remote and proximal sensing, computer programming) in order to put into a quantitative framework the spatiotemporal study of soils (McKenkie and Ryan, 1999; McBratney et al., 2003). DSM overcomes some serious limitations of conventional soil mapping such as the description of soil variability. DSM emphasises the soil continuum, where soil properties at a given location depend also on their geographic position and on the soil properties at neighbouring locations, and then overcome limitations and coarseness of using large discrete polygons as a means of describing soil variability in the landscape in both the geographic and the attribute domains.

One of the most interesting outputs of such DSM methods may be the spatial distribution of the prediction error (soil type and soil attributes); this can be usefully employed in applying hydrological modelling at the landscape scale.

Despite all the important advances by DSM, unfortunately it is rather evident (e.g. Jones et al., 2005) that, at the present day, in most countries, regions, municipalities and so forth, classical soil maps still constitute the only real soil data available - and usable - for landscape and watershed hydrology. This is not surprising considering that DSM is still a young approach in soil mapping and typically requires soil datasets with associated higher costs (Manna et al., 2009) that must be counterbalanced by higher earnings to be sustainable (Verhagen et al., 1995).

Analysing the relationships between soil maps and hydrology it seems clear that there has been some progress. For instance in Table 1 are given references to few digital soil mapping works providing spatial analysis of soil parameters relevant for hydrology. But despite the progress made on the subject, the scientific literature (e.g. McBratney et al., 2003; Grunwald, 2009) is rather devoid of critical and analytical evaluation concerning the use of soil map information (both traditional and/or obtained by DSM) aiming specifically to contribute in watershed related hydrological studies.

The lack of scientific literature on this crucial question is rather regrettable and indeed surprising and it is possibly related to the evidence (by surveying the scientific literature and from the few references quoted above) that at present hydropedology has been very much driven by soil hydrologists rather than pedologists, who are indeed the experts producing soil maps. In this regard, our contribution, which emphasises pedological issues, it may both provide a new outline for hydropedology and a new framework for approaching hydrological problems at the landscape scale.

In this context, going beyond the generic statement concerning the importance of hydropedology, we believe it is of the utmost importance to examine whether and to what extent soil maps (and associated soil data), produced in accordance with different aims, scales and procedures (conventional or by DSM), can play a role in hydrological applications at the landscape scale. This work aims to address the above question, focusing on the hydrological potential and limitations of soil surveys and soil mapping.

In this paper, having provided in Appendix A the description of the process of making soil maps, we perform an analytical evaluation, from a hydrological perspective, of the database associated to soil maps. We then show ways to reinforce and to rethink the interaction between pedology and landscape hydrology also exploring alternative strategies that can be followed according to the soil data availability, using some relevant case studies from Italy. For the sake of intelligibility we provided in Appendix $\mathrm{C}$ a short description of the models applied in the case studies.

\section{An evaluation of soil mapping data from an hydrological perspective}

\subsection{Content and availability of soil maps and soil database}

The final result of soil surveying and soil mapping is then the production of a georeferenced soil database containing all the information obtained from field work and laboratory analysis, along with GIS vector data containing the geometry of the soil mapping unit polygons (see Appendix A). Hitherto the same information was produced in analog format. 
Table 1. Selection of works involved in soil mapping and hydrologically relevant parameters.

\begin{tabular}{|c|c|c|c|c|}
\hline Author (year) & Attributes & $\begin{array}{l}\text { No } \\
\text { observations }\end{array}$ & $\begin{array}{l}\text { Cartographic } \\
\text { scale }(1: x)\end{array}$ & $\begin{array}{l}\text { Study Area } \\
\left(\mathrm{km}^{2}\right)\end{array}$ \\
\hline McKenzie and Austin (1993) & $\begin{array}{l}\text { clay content, CEC, EC, pH, } \\
\text { bulk density and COLE }\end{array}$ & 224 & 100000 & 500 \\
\hline Zheng et al. (1996) & available water capacity & - & - & - \\
\hline Cialella et al. (1997) & drainage classes & - & 12000 & 24 \\
\hline Voltz et al. (1997) & wiliting point & 426 & 100000 & 17,36 \\
\hline Obertur et al. (1999) & soil texture classes & 384,208 & 100000 & 192,39 \\
\hline Chaplot et al. (2000) & $\begin{array}{l}\text { redoximorphic features, } \\
\text { hydromorphy index }\end{array}$ & 182 & - & 0.2 \\
\hline Lagacherie and Voltz (2000) & wilting point & 374 & 100000 & 20 \\
\hline McBratney et al. (2000) & clay content, CEC & $\begin{array}{l}95 \\
180 \\
734\end{array}$ & $\begin{array}{l}2000 \\
200000 \\
500000\end{array}$ & $\begin{array}{l}0.42 \\
1100 \\
45600\end{array}$ \\
\hline Campling et al. (2002) & soil drainage classes & $295+72$ & 50000 & 589 \\
\hline Kravchenko et al. (2002) & $\begin{array}{l}\text { electrical conductivity, } \\
\text { soil drainage }\end{array}$ & 107 & - & 0.2 \\
\hline Jost et al. (2005) & water storage & 195 & & 0.005 \\
\hline Agyare et al. (2007) & $\begin{array}{l}\text { texture, } \mathrm{pH}, \mathrm{OC}, \mathrm{CEC}, \\
\text { bulk density, saturated } \\
\text { hydraulic conductivity }\end{array}$ & 600,400 & - & $6,0.64$ \\
\hline Shrestha et al. (2008) & $\begin{array}{l}\text { water-holding capacity, } \\
\text { saturated hydraulic } \\
\text { conductivity, hydrologically } \\
\text { active layer depth, soil } \\
\text { texture, rainfall }\end{array}$ & 165 & - & 3550 \\
\hline Joel et al. (2009) & $\begin{array}{l}\text { texture, groundwater } \\
\text { level, occurrence of poorly } \\
\text { permeable layers }\end{array}$ & - & $\begin{array}{l}50000 \text { to } \\
100000\end{array}$ & 7260 \\
\hline
\end{tabular}

Basically, in conventional mapping the final soil map and its corresponding database include (i) $n$ soil mapping units; (ii) one (or more) main soil type for each of these $n$ mapping units (typically named soil typological units); (iii) then at each soil type are assigned field and lab data obtained from a representative soil. The choice of this representative soil (also named benchmark soil) is rather important and it is based on expert (pedologist) judgement aiming to identify which of the $n$ soils of a specific type is both dominant and best represents the modal concept. This soil can be either a true soil (e.g. Soil Survey Division Staff, 1993) or a virtual soil obtained after a weighted mean procedure (e.g. Lambert et al., 2003). Finally, (iv) some interpretations for practical purposes are also provided.

In the case of digital soil mapping, such final soil map (produced after a spatial inference system) more often refer to the mapping of specific soil properties but the starting "soil data" indeed include the same soil database of conventional mapping - but can also include (i) and (ii). Then both conventional and digital soil mapping rely on the same basic soil database (also in terms of potentials and limitations).

Here it is important to emphasise that, typically, the database behind a soil map is rather ponderous. For instance assuming a soil observation (profile) consisting of only three horizons, the potential output for a standard field description may include about 181 field data (31 for site description; 50 characteristics to be described for each of the three soil horizon) and 36 laboratory-based data for "each soil observation".

This ponderous spatial database can be very important for hydrologists because it can be easily assumed that most features are directly or indirectly connected to either/both water fluxes and permanence of water in soils. An example of the kind of soil features that are described and then present in soil databases is given in Table 2 - later discussed - where we have highlighted in bold and italics those features that are of great relevance to hydrology. 
Table 2. Example of soil features typically found in a pedological description. Numbers indicate the amount of sub-characters supplying each feature.

\begin{tabular}{|c|c|c|c|}
\hline $\begin{array}{l}\text { Field analysis at the } \\
\text { soil survey station } \\
\text { ( } 31 \text { features) }\end{array}$ & $\begin{array}{l}\text { Field analysis of } \\
\text { the soil profile } \\
\text { ( } 73 \text { features } \\
\text { per horizon) }\end{array}$ & $\begin{array}{l}\text { Laboratory analysis } \\
\text { of the soil profile } \\
\text { (12 features } \\
\text { per horizon) }\end{array}$ & $\begin{array}{l}\text { Process for determining water and } \\
\text { temperature regime in soil taxonomy } \\
\text { (monthly data from weather stations } \\
\text { nearby) }\end{array}$ \\
\hline Location & Type of horizon & $\mathrm{pH}\left(\mathrm{H}_{2} \mathrm{O}\right)$ & Rainfall \\
\hline Type of observation & Matrix colour 4 & $\overline{\mathrm{pH}(\mathrm{KCI})}$ & Temperature \\
\hline Soil surveyors & Concentrations 5 & CEC & $\overline{\mathbf{E T}_{\mathrm{p}}}$ \\
\hline Lithology & Coatings 6 & Exchangeable bases & \\
\hline$\overline{\text { Land use }}$ & Slickensides 2 & Carbonates & \\
\hline Vegetation & Biological activity 2 & Total $N$ & \\
\hline Morphology & Carbonates & $\overline{\text { Electrical conductivity }}$ & \\
\hline Curvature & Roots 3 & Organic carbon & \\
\hline Erosion 2 & Mottles 4 & Granulometry & \\
\hline Deposition & Coarse fragments & & \\
\hline Rotting depth & $>2 \mathrm{~mm}) 5$ & & \\
\hline Depth to rock & Texture 3 & & \\
\hline Parent material 3 & Consistency 3 & & \\
\hline Elevation & Structure 6 & & \\
\hline Slope & Pores 2 & & \\
\hline$\overline{\text { Exposure }}$ & Cracks 2 & & \\
\hline Vegetation cover & Boundaries 2 & & \\
\hline \multicolumn{4}{|l|}{$\overline{\text { Rockiness }}$} \\
\hline \multicolumn{4}{|l|}{$\overline{\text { Stoniness } 2}$} \\
\hline \multicolumn{4}{|l|}{ Runoff } \\
\hline \multicolumn{4}{|l|}{ Crack 3} \\
\hline \multicolumn{4}{|l|}{ Groundwater } \\
\hline \multicolumn{4}{|l|}{ Flood } \\
\hline \multicolumn{4}{|l|}{ Internal drainage } \\
\hline \multicolumn{4}{|l|}{ Permeability } \\
\hline Estimated AWC & & & \\
\hline
\end{tabular}

Normal: soil features of low hydrological interest; italics: soil features of indirect hydrological interest; bold: soil features of direct interest in hydrology; underlined: quantitative evaluation; not underlined: qualitative and semi quantitative evaluation.

Examples of such soil databases and vector data themes may be found on the web (e.g. in the USA). Soil maps can be easily accessed through services such as web soil survey programs at national scale (e.g. in the USA http://websoilsurvey. nrcs.usda.gov) or also at regional level (e.g. https:// applicazioni.regione.emilia-romagna.it/cartografia_sgss).

The availability of soil maps (and associated databases) varies from country to country and their quality is often related to the presence of soil survey agencies. It has been estimated (Dobos et al., 2006) that over 500000 detailed soil profiles have been described in EU countries in the last 2030 years. In the EU despite this potential, unfortunately many national institutions (which typically commissioned soil maps) are unwilling to reveal soil data; they only provide processed generalized products (Rossiter, 2004). By contrast, in the USA soil datasets are easily accessible (http: //www.nrcs.usda.gov). The availability of soil maps obtained through DSM procedures and with a hydrological content is still rather limited (Table 1) but it embeds high potential in future prospects.

Despite this complex and heterogeneous scenario, already reported in Dobos et al. (2006) and Jones et al. (2005), many European regions are gradually moving to adopt standardization such as the case concerning the scale of conventional soil maps. At present, the latter are generally produced at the inventory (1:250 000) and semidetailed (1:50000) scales.

The 1:250000 scale aims at an inventory of regional soil resources. Most European countries either already have such maps or are in the process of obtaining them. The 1:50000 semidetailed scale, because of their better spatial information (higher number of soil observation per unit area), aims to produce soil information directly usable in planning and land management (mainly in agriculture and forestry) but also possibly in landscape hydrology. Availability of these semi-detailed soil maps varies greatly since there is a marked discrepancy in map coverage from several European regions 
and most of the mapped areas refer to plains. This situation, to be regretted from a hydrological viewpoint (plains are just one component of a catchment), is due to the fact that public agriculture departments, aiming at better agriculture management, are the main financiers of such maps. At this scale in many countries, hill and mountain areas are rarely included in such maps. In this paper we do not aim to go further into the subject of soil mapping. However, soil map content (e.g. data from specific soil mapping units) can be easily browsed for specific areas by searching through the many dedicated websites (such as those given above).

From this scenario, regardless the scale, it is important to emphasise that soil mapping, being heavily financed by agricultural departments and organizations, is strongly focused on providing answers to agricultural questions (e.g. chemical and physical fertility, C stock, soil productivity) and then hydrological answers must be found from this basis, which is anyway a very valuable basis.

Moreover, standard soil mapping does not provide true quantitative information as to ensure detailed soil spatial variability and related spatial uncertainty. In the scientific literature there are a few cases where this information has been produced ex post but in most localities this spatial information cannot be retrieved mainly due to (i) loss of data and (ii) customers (e.g. administrative regions) who commissioned the soil survey (in many cases long ago) only rarely allow access to the original soil information in their possession (if they still have it). In fact standard publication of soil maps, soil reports (both in analog and/or digital format) and even soil database do not include all the produced soil information but rather an extensive summary based on the main soil types (reference profiles) and the related landscape features. Although a fairly standardized process produces this summary (e.g. Soil Survey Division Staff, 1993) where much care is taken to ensure internal consistency, it does not provide a tool to investigate the spatial variability of soils between and especially within the soil mapping units.

On this base, it is important to emphasise that in the following sections we shall focus our hydrological evaluation to the only information contained in soil databases. More specifically, we shall not attempt any hydrological oriented examination of other important soil documents such as soil map legends/reports (as typically reported in shape files or in analog maps) or soil classification classes. This is because soil map legends and reports provide a synopsis of soil information where parameters which originally may be important for hydrology are not anymore available being embedded and aggregated along with other information in the process of soil mapping. This situation also applies to soil classification. In fact pedologists typically classify soils, indeed using updated international soil classification schemes (e.g. Soil Taxonomy: USDA, 2010; World Reference Base: WRB, 2006) that are still very much developing in the framework of agriculture/forestry (e.g. FAO, USDA) rather than in hydrology. Then hydrological features (e.g. field estimate of infiltration and runoff, water retention at specific pressure heads, etc.), if present, in the best of the cases have been employed as one of the many parameters enabling the soil classification. Then, in some cases, the only final soil classification may be far from giving the indication of the soil hydrological behaviour. The worse outcoming result is that soils classified with the same name may have a rather different hydrological behaviour. Then, from our viewpoint, it is better to focus our analysis on actual database rather than on soil classification as given in standard soil legend/report.

\subsection{An analytical evaluation of potentials and limitations in using soil mapping data in landscape hydrology}

Hydrological analysis of the soil map and its database must really start from its information content. Then in order to shed some hydrological light on these soil features occurring in typical soil databases, we reclassified them in accordance with their direct, indirect and low hydrologic relevance. More specifically, in Table 2 we have highlighted in bold (direct) and italics (indirect) those features contained in the soil mapping databases that are of great relevance to hydrology. This classification has the form of a general suggestion, mainly because in some cases the boundaries between these classes are not sharp.

In theory, any of these soil features, also those classified as low hydrologic relevance, have a potential (direct/indirect) interest in hydrology; for instance soil $\mathrm{pH}$, governing the composition of the soil solution and influencing ion exchange on clay minerals, can greatly affect aggregation and hence soil porosity and eventually hydrological behaviour. However, soil $\mathrm{pH}$, even if strongly influencing the soil system and thus potentially the hydraulic properties, has no direct quantitative relationship with them. This is because $\mathrm{pH}$ is only one of the many soil features (and processes) occurring at different spatial scales and governing soil porosity and then in turn soil hydraulic properties, infiltration rate, runoff, etc. Then features, such as soil $\mathrm{pH}$, have been considered having low hydrologic relevance.

An example of feature having an indirect hydrologic relevance is for instance the occurrence of iron coatings; in fact in many soils they can be assumed as an indirect indicator of severe water stagnation (even if water may be not present at the time of soil observation).

Among the data having a direct hydrologic relevance and also directly applicable in hydrological modelling we just recall the texture and organic carbon for an easy estimate of hydraulic properties by PTF (Pachesky and Rawls, 2004), the horizons boundaries for the schematization of the water field flow, and the depth of the water table for fixing bottom boundary condition.

Given the complexity of the issue and the need to go into the hydrological usability of data presented in soil databases, we limited our analysis at the only features (19) that have 
Table 3a. Types of data of great (and direct) hydrological interest contained in soil map databases.

\begin{tabular}{|c|c|c|c|c|c|}
\hline $\begin{array}{l}\text { Type of soil } \\
\text { feature }(\mathrm{N} \text {. of } \\
\text { sub-feature }\end{array}$ & Description of the feature & Method & Methodological description & Main potential & Main limitations \\
\hline Cracks (3) & $\begin{array}{l}\text { Occurence of cracks at the } \\
\text { soil surface }\end{array}$ & $\mathrm{SQT}^{3}$ & $\begin{array}{l}\text { Estimate (using comparative tables and metric } \\
\text { measurements) of frequency, width and depth of } \\
\text { cracks }\end{array}$ & $\begin{array}{l}\text { It is evidence of } \\
\text { processes of preferential } \\
\text { water and pollutant } \\
\text { flows (bypass flow) }\end{array}$ & $\begin{array}{l}\text { It is a strongly anisotropic parameter, non- } \\
\text { linear function of the water content in soil }\end{array}$ \\
\hline Groundwater & $\begin{array}{l}\text { Occurence of groundwater } \\
\text { in the investigated soil } \\
\text { profile }\end{array}$ & $\mathrm{QL}^{2}$ & $\begin{array}{l}\text { Assessment made both on the basis of direct } \\
\text { observations in the soil profile along with indirect } \\
\text { information (interviews with farmers, land } \\
\text { reclamation consortia, etc.) }\end{array}$ & $\begin{array}{l}\text { Basic environmental } \\
\text { data }\end{array}$ & $\begin{array}{l}\text { Strongly quality-based and time } \\
\text { dependent assessment }\end{array}$ \\
\hline Floods & Flood risk & $\mathrm{QL}^{2}$ & $\begin{array}{l}\text { Estimate of morphometric, morphodynamic and } \\
\text { hydraulic factors governing flood risk }\end{array}$ & $\begin{array}{l}\text { Basic environmental } \\
\text { data }\end{array}$ & Rather subjective evaluation \\
\hline Runoff & Runoff estimate & $\mathrm{QL}^{2}$ & $\begin{array}{l}\text { The class of runoff (from very low to very high) } \\
\text { is established using a table. Slope angle and } K_{\text {sat }} \\
\text { (or its estimate) must be known. }\end{array}$ & $\begin{array}{l}\text { Basic environmental } \\
\text { data }\end{array}$ & $\begin{array}{l}\text { It is a subjective measurement because } K_{\text {sat }} \\
\text { is rarely known. Hence assessment is made } \\
\text { by "expert best estimate" }\end{array}$ \\
\hline $\begin{array}{l}\text { Internal } \\
\text { drainage }\end{array}$ & $\begin{array}{l}\text { Estimate of water removal } \\
\text { rate in the soil profile }\end{array}$ & $\mathrm{QL}^{2}$ & $\begin{array}{l}\text { Assessment on the basis of slope, texture } \\
\text { skeleton, presence of horizons with low } \\
\text { permeability and also hydromorphic horizons }\end{array}$ & $\begin{array}{l}\text { It is a feature governing } \\
\text { infiltration and runoff } \\
\text { process }\end{array}$ & $\begin{array}{l}\text { Strongly quality-based assessment on a } \\
\text { parameter which is very difficult to } \\
\text { estimate }\end{array}$ \\
\hline $\begin{array}{l}\text { Estimated } \\
\text { AWC }\end{array}$ & $\begin{array}{l}\text { Estimate of Available Water } \\
\text { Capacity for vegetation }\end{array}$ & $\mathrm{QL}^{2}$ & $\begin{array}{l}\text { Assessment based on texture, organic matter, } \\
\text { bulk density, rock fragments, salinity, roots and } \\
\text { soil horizon depth. Assessment is made by using } \\
\text { tabular data and empirical formulas. }\end{array}$ & $\begin{array}{l}\text { It is a feature governing } \\
\text { infiltration and runoff } \\
\text { processes }\end{array}$ & $\begin{array}{l}\text { Many of the parameters required for this } \\
\text { evaluation are highly subjective and } \\
\text { qualitive }\end{array}$ \\
\hline Boundaries (2) & $\begin{array}{l}\text { Lower limit of horizons. It is } \\
\text { the thickness of each horizon }\end{array}$ & $\mathrm{QT}^{1}$ & Metric measurements $(\mathrm{cm})$ & $\begin{array}{l}\text { Essential basic } \\
\text { information }\end{array}$ & $\begin{array}{l}\text { This parameter can have marked spatial } \\
\text { variability }\end{array}$ \\
\hline Mottles (4) & $\begin{array}{l}\text { Patches of different colours } \\
\text { (usually related to Fe and/or } \\
\text { Mn), on the surface of the } \\
\text { aggregates produced by } \\
\text { waterlogging }\end{array}$ & $\mathrm{SQT}^{3}$ & $\begin{array}{l}\text { It describes the colour (Munsell Tables), } \\
\text { frequency (visual estimate using comparative } \\
\text { tables), size (metric measurement), contrast, } \\
\text { limits and location of the mottles. }\end{array}$ & $\begin{array}{l}\text { This information enables } \\
\text { the assessment of the } \\
\text { (relative) degree of water } \\
\text { stagnation (even if water } \\
\text { is absent at the time of } \\
\text { soil description) }\end{array}$ & $\begin{array}{l}\text { The size of the mottles depends also on } \\
\text { the soil chamical conditions (e.g. pH) and } \\
\text { on the behaviour of the different ionic } \\
\text { forms of iron and manganese. The mottles } \\
\text { may have been produced in a climate } \\
\text { different from the present day (e.g. } \\
\text { paleoclimate) }\end{array}$ \\
\hline
\end{tabular}

Abbrev: ${ }^{1}$ QT: quantitative; ${ }^{2}$ QL: qualitative; ${ }^{3}$ SQT: semiquantitative.

a great hydrologic relevance. Hence, in Table 3 their main potential and limitations have been reported along with the information if the method by which this data is obtained was qualitative, semiquantitative or quantitative.

A detailed analysis of the table shows that at any feature corresponds a hydrological potential; then this potential could become even larger considering that many soil features occur in soils at the same time and then their ensemble can provide integrated hydrological information. But in order to exploit this potential it is also fundamental to understand associated limitations.

Then on this base below we discuss, using some examples given in the table, the two main types of limitation that should be taken into account using these data, namely data interpretation and quality of the estimate of soil features.

\section{a. Data interpretation}

Soils are complex bodies and some features need an expert interpretation. In order to show this point, one soil feature worth mentioning, because having a close interaction with soil hydrology, is the occurrence of coatings in soils. Those are soil material typically deflocculated, transported and deposited (flocculated) in lower horizons. Water is a crucial factor affecting the occurrence of these soil features and then we would expect that their occurrence and quantification could help us in understanding underlying soil hydrological processes. Unfortunately the issue is far more complex, in fact we must consider the following: (i) coatings can be of different type such as clay, silt, organic matter etc.; then the physics governing each of these type of materials is different and it is very indeed much affect by the particle size. For instance, the usually called clay coatings are typically fine clay coatings $(<0.2$ microns $)$ because mainly fine clay is likely to easily pass through the filtering action of soils. Then this fine clay can move both in very small and very large pores (where preferential flow occurs) and then the hydrological significance of coatings must be related to this complexity. The next issue (ii) is that coatings can move both vertically and horizontally and therefore their hydrological meaning is not unique. Moreover (iii) the field quantification of these features is not always easy and its detecting (even with magnifying lenses) depends by the degree of colour contrasts between the coatings themselves and the soil matrix; finally, (iv) coatings can be formed (pedorelict) under different climatic condition (e.g. paleoclimate). 
Table 3b. Types of data of great (and direct) hydrological interest contained in soil map databases.

\begin{tabular}{|c|c|c|c|c|c|}
\hline $\begin{array}{l}\text { Type of soil } \\
\text { feature (No. of } \\
\text { sub-features to } \\
\text { be described) }\end{array}$ & Description of the feature & Method & Methodological description & Main potential & Main limitations \\
\hline $\begin{array}{l}\text { Coarse } \\
\text { fragments (5) }\end{array}$ & $\begin{array}{l}\text { Estimate of soil particles } \\
\text { larger than } 2 \mathrm{~mm} \text { (in the } \\
\text { field) }\end{array}$ & $\mathrm{SQT}^{3}$ & $\begin{array}{l}\text { Describes size (metric measurement), shape } \\
\text { (using reference diagrams), lithology and } \\
\text { frequencey (visual estmate using comparative } \\
\text { tables) of particles }>2 \mathrm{~mm}\end{array}$ & $\begin{array}{l}\text { It is essential } \\
\text { information for } \\
\text { calculating water } \\
\text { balance in soil }\end{array}$ & Visual estimate by comparative tables \\
\hline Texture (3) & $\begin{array}{l}\text { Estimate of soil particles } \\
\text { smaller than } 2 \mathrm{~mm} \text { (in the } \\
\text { field) }\end{array}$ & $\mathrm{SQT}^{3}$ & $\begin{array}{l}\text { Assessment, using standardized tactile tests } \\
\text { schemes (e.g. USDA), of textural class and/or \% } \\
\text { estimate of sand, silt and clay }\end{array}$ & $\begin{array}{l}\text { Essential parameter to } \\
\text { estimate many } \\
\text { hydrological } \\
\text { parameters }\end{array}$ & $\begin{array}{l}\text { Evaluation of } \% \text { data by tactile test } \\
\text { requires much experience an also } \\
\text { calibration on the specific soils under } \\
\text { investigation }\end{array}$ \\
\hline Structure (3) & Analysis of soil aggregates & $\mathrm{QL}^{2}$ & $\begin{array}{l}\text { Description of type (comparison with diagrams), } \\
\text { size (metrical analysis) and degree of destinctness } \\
\text { of the aggregates in soils }\end{array}$ & $\begin{array}{l}\text { It is a feature strongly } \\
\text { governing the } \\
\text { dynamics of water and } \\
\text { pollutants in soil }\end{array}$ & $\begin{array}{l}\text { It is a feature described by a strongly } \\
\text { qualitative assessment }\end{array}$ \\
\hline Pores (3) & $\begin{array}{l}\text { Estimate of soil } \\
\text { macroporosity (pores } \\
>0.1 \mathrm{~mm} \text { ) }\end{array}$ & $\mathrm{SQT}^{3}$ & $\begin{array}{l}\text { Description of size, frequency and shape } \\
\text { (comparative tables) of macropores, using a } \\
\text { magnifying glass }(10 \mathrm{X})\end{array}$ & $\begin{array}{l}\text { It is a feature, } \\
\text { connected to structure, } \\
\text { which strongly } \\
\text { affects water and } \\
\text { pollutant dynamics }\end{array}$ & $\begin{array}{l}\text { It is a rather difficult feature to be } \\
\text { determined. It is appraised by a strongly } \\
\text { quality-based assessment. }\end{array}$ \\
\hline $\begin{array}{l}\text { Internal cracks } \\
\text { (2) }\end{array}$ & $\begin{array}{l}\text { Occurence of cracks within } \\
\text { a soil horizon }\end{array}$ & $\mathrm{SQT}^{3}$ & $\begin{array}{l}\text { Frequency estimate (comparative tables) of both } \\
\text { width an depth of cracks (metric measurements) } \\
\text { in soil horizons }\end{array}$ & $\begin{array}{l}\text { Sign of potential } \\
\text { bypass flow processes }\end{array}$ & $\begin{array}{l}\text { Parameter strongly anisotropic with non- } \\
\text { linear function of the soil water content }\end{array}$ \\
\hline $\begin{array}{l}\text { Consistence } \\
\text { (5) }\end{array}$ & $\begin{array}{l}\text { Soil features related to } \\
\text { cohesion and adhesion }\end{array}$ & $\mathrm{QL}^{2}$ & $\begin{array}{l}\text { Description of consistence and plasticity of soil } \\
\text { aggregates by means of their resistance to hand } \\
\text { breakage, type of breakage, degree of } \\
\text { cementation, adhesiveness and plasticity. }\end{array}$ & $\begin{array}{l}\text { It is another feature } \\
\text { that, by influencing } \\
\text { soil structure, can also } \\
\text { affect soil hydrologic } \\
\text { behaviour }\end{array}$ & $\begin{array}{l}\text { It is a feature determined by a strongly } \\
\text { quality-based assessment }\end{array}$ \\
\hline Andic & $\begin{array}{l}\text { Occurence of } \\
\text { short-range order } \\
\text { clay minerals and/or } \\
\text { Al/Fe-humus complexes }\end{array}$ & $\mathrm{QL}^{2}$ & $\begin{array}{l}\text { Field test by } \mathrm{pH} \text { estimate (by phenolphthalein } \\
\text { indicator) after sodium fluoride addition. Colour } \\
\text { intensity of the reaction is correlated with andic } \\
\text { properties }\end{array}$ & $\begin{array}{l}\text { It is a feature strongly } \\
\text { affecting hydrological } \\
\text { properties }\end{array}$ & $\begin{array}{l}\text { It is a property determined by a strongly } \\
\text { quality-based assessment }\end{array}$ \\
\hline
\end{tabular}

Abbrev: ${ }^{1}$ QT: quantitative; ${ }^{2}$ QL: qualitative; ${ }^{3}$ SQT: semiquantitative.

Nevertheless, despite these cautions, indeed coatings, if well recognized and defined, can tell us something important about which type of hydrological process take (took) place in the soils (e.g. preferential flow) and then their occurrence and their interpretation (between options i, ii, iii and iv) can be much profitable from an hydrological viewpoint.

Another case worth mentioning concerns mottles. Their occurrence (frequency, size, location) is a very important index for assessing water saturation patterns, even if water is not present at the specific time of soil survey. This is certainly true, but again some caution must be taken if these mottles refer to iron or manganese: these two elements have rather different solubility at different $\mathrm{pH}$ and redox potentials. For instance, if two soils show very different $\mathrm{pH}$ values, then the same mottles may indicate rather different hydrological conditions. In addition, mottles can occur as the result of ancient water saturation processes, such as those occurring for instance in many Italian palaeosols in the Po Valley. An expert pedologist knowing the study area can easily make these cautionary interpretations of mottles.
A special case to be mentioned refers to the occurrence of andic properties (also named here as andic features). In this case much caution should also be used in applying PTF in soils showing marked andic features (see Appendix B) for the occurrence of specific and highly reactive clay minerals, namely low order clay minerals (allophane-like). These specific features lend these soils with distinctive physical and chemical characteristics that are not found in soils derived from other parent materials under the same vegetation and climate. Particularly, they are well structured (at the surface) showing both high specific surface $\left(600 \mathrm{~m}^{2} \mathrm{~g}^{-1}\right)$ and large volume of micropores and macropores (Yong and Warkentin, 1975). Andic features are then responsible for the high values of water retention and water conductivity but also high Cation Exchange Capacity (CEC); they all strongly affect water and solute fluxes. As consequence (i) in these soils standard PTF cannot be applied because the standard relationships texture-hydraulic properties have been all set with respect to soils having crystalline clays (Basile et al., 1999); moreover, (ii) due to this distinctive features, there are well known artefacts (Nanzyo et al., 1993) in 
Table 3c. Types of data of great (direct and indirect) hydrological interest contained in soil map databases.

\begin{tabular}{|c|c|c|c|c|c|}
\hline $\begin{array}{l}\text { Type of soil feature } \\
\text { (No. of sub-features } \\
\text { to be described) }\end{array}$ & $\begin{array}{l}\text { Description of } \\
\text { the feature }\end{array}$ & Method & Methodological description & Main potential & Main limitations \\
\hline Clay coatings (6) & $\begin{array}{l}\text { Coatings of clay } \\
\text { material (usually } \\
\text { fine clay) as } \\
\text { occuring in } \\
\text { pores and over } \\
\text { aggregates }\end{array}$ & $\mathrm{SQT}^{3}$ & $\begin{array}{l}\text { It describe the colour (Munsell Tables), frequency (visual } \\
\text { estimate using comparative tables) size (metric } \\
\text { measurement) and location of clay coatings }\end{array}$ & $\begin{array}{l}\text { It is an evidence of } \\
\text { processes of preferential } \\
\text { water and pollutant flows }\end{array}$ & $\begin{array}{l}\text { Occurence clay coatings depends also by } \\
\text { soil chemisty (e.g. ions in soil solution, } \\
\text { exchangeable sodium). Coatings may have } \\
\text { been produced in a past climate different } \\
\text { from the presend day (e.g. paleoclimate) }\end{array}$ \\
\hline $\begin{array}{l}\text { Iron }(\mathrm{Fe}) \text { and } \\
\text { manganese }(\mathrm{MN}) \\
\text { coatings (6) }\end{array}$ & $\begin{array}{l}\text { Fe and Mn } \\
\text { coatings are } \\
\text { occuring in } \\
\text { pores and over } \\
\text { aggregates }\end{array}$ & $\mathrm{SQT}^{3}$ & $\begin{array}{l}\text { It describe the colour (Munsell Tables), frequency (visual } \\
\text { estimate using comparative tables), size (metric } \\
\text { measurement) and location of } \mathrm{Fe}-\mathrm{Mn} \text { coatings }\end{array}$ & $\begin{array}{l}\text { It is an evidence of } \\
\text { reducing condition as } \\
\text { occuring in water } \\
\text { stagnation. Fe coatings } \\
\text { more pronounced water } \\
\text { stagnation as compared to } \\
\text { Mn coatings. }\end{array}$ & $\begin{array}{l}\text { Occurence of Fe-Mn coatings depends also } \\
\text { by soil chemistry and on the diffent ionic } \\
\text { forms of iron and manganese in soil } \\
\text { solution. Fe-Mn coatings may have been } \\
\text { produced in a past climate different from } \\
\text { the present day (e.g. paleoclimate) }\end{array}$ \\
\hline Granulometry & $\begin{array}{l}\text { Laboratory } \\
\text { analysis of the } \\
\text { particel size } \\
\text { classes (at least } \\
\text { sand, silt and } \\
\text { clay }\end{array}$ & $\mathrm{QT}^{1}$ & $\begin{array}{l}\text { Analysis of frequency of coarse fragments, coarse sand, fine } \\
\text { sand, silt and clay (e.g. pipette method or hydrometer } \\
\text { method). } \\
\text { Since soil particles can be agrregated by organic or inorganic } \\
\text { cementing agents, real granulometric analysis (after } \\
\text { dissolving all cements) or apparent granulometric analysis } \\
\text { (no pretreatments) can be performed. }\end{array}$ & $\begin{array}{l}\text { Basic information for } \\
\text { many hydrological } \\
\text { evaluations. It is a very } \\
\text { robust parameter } \\
\text { governing many physical } \\
\text { process }\end{array}$ & $\begin{array}{l}\text { Soils with similar granulomatry can still } \\
\text { have very different hydrological behaviour } \\
\text { This is especially the case for permeability, } \\
\text { which depends on meso and macropores, } \\
\text { but also for water retention properties, } \\
\text { which can change according to clay } \\
\text { mineralogy (kaolinite versus smectite ratio) }\end{array}$ \\
\hline Organic carbon & $\begin{array}{l}\text { Laboratory } \\
\text { analysis of } \\
\text { organic C } \\
\text { content }\end{array}$ & $\mathrm{QT}^{1}$ & $\begin{array}{l}\% \text { of organic C (e.g. typically performed after dichromate } \\
\text { oxidation method) }\end{array}$ & $\begin{array}{l}\text { It is a soil feature that } \\
\text { strongly affects soil } \\
\text { structure, porosity and } \\
\text { hence many physical } \\
\text { processes }\end{array}$ & $\begin{array}{l}\text { Soils with the same organic carbon content } \\
\text { may have very different physical properties }\end{array}$ \\
\hline Water Regime & $\begin{array}{l}\text { Simplified water } \\
\text { balance }\end{array}$ & $\mathrm{QT}^{1}$ & $\begin{array}{l}\text { This analysis is generelly performed to classify soils } \\
\text { according to the Soil Taxonomy (USDA) scheme. Examples } \\
\text { include Xeric, Ustic, Udic, Aquic moisture regime. This } \\
\text { analysis consists in a simplified water balance on the basis of } \\
\text { monthly rainfall and evapotranspiration data and of soil } \\
\text { AWC. Evaluation is made using bucket-based models (e.g. } \\
\text { Billeaux, Newhall) for a specific soil depth (control section) }\end{array}$ & $\begin{array}{l}\text { It is a rather synthetic but } \\
\text { very useful assessment. It } \\
\text { is strongly associated to } \\
\text { the physical reality of } \\
\text { soils }\end{array}$ & $\begin{array}{l}\text { The assessment of the "water regime" is } \\
\text { very much affected by the coarse quality of } \\
\text { inputs (i.e. monthly time based inputs). This } \\
\text { is the case for AWC, rainfall and } \\
\text { evapotranspiration. It is a description of a } \\
\text { rather "static" water balance. }\end{array}$ \\
\hline
\end{tabular}

Abbrev: ${ }^{1}$ QT: quantitative; ${ }^{2}$ QL: qualitative; ${ }^{3}$ SQT: semiquantitative.

standard texture analysis due to the dispersion procedure engendering an apparent coarser texture than the real one. Finally, (iii) solute transport in andic soils can be characterized by the occurrence of both chemical and physical exclusion. The presence of large negative charges on some surface particles results in the chemical repulsion of anions from these regions (Bolt, 1982); moreover due to the occurrence of very high average pore water velocity, a portion of the water in the micropores can be considered relatively immobile and therefore excluded by the flow. Such unusual but crucial characteristics of these soils are difficult to be estimated by indirect methods; hence typically they should be determined either experimentally or by carefully studying the limited available literature (Bartoli et al., 2007).

Then, as final remarks, all the above examples prove both that some soil features present in soil database can be potentially profitable for hydrologist but also that the help of an expert (hydro)pedologist is a must for a correct interpretation of those features occurring in a specific piece of landscape.

This is even more important considering that many soil features (e.g. clay coatings and mottles) can occur at the same time in soils and then their corrected compound interpretation (e.g. preferential flow and seasonal water stagnation) can profit very much from this simultaneous occurrence. Finally the simultaneous occurrences of features (e.g. mottles, Fe coatings) having a similar hydrological meaning (e.g. water stagnation) enable to have a further cross validation for a correct interpretation.

\section{b. Quality of the estimate/measurement of soil features} In soil databases almost all parameters have a sort of quantitative formalization. In reality, the methods by which this information is obtained may be qualitative, semiquantitative or quantitative, as illustrated in Tables 2 and 3 and these methodological differences are important if this information have to be effectively employed in hydrology (e.g. parameterization of hydrological models).

For example, the analysis of water balance, using bucket-based models, might induce one to assume that a soil database provides high quality data for hydrological applications. Unfortunately this is not always the case because, for example, the AWC (Available Water Capacity, the reference water storage in the rhizosphere) is calculated on the basis of particle size classes by means of a not calibrated PTF and not through direct measurement; furthermore, the particle size classes themselves 
can be obtained by a laboratory measurement or even more by a field estimate (Table 3a). Nevertheless knowing these cautionary notes, indeed simplified water balance as occur in reports and even in some soil type classifications (Soil Taxonomy) can be very informative and useful in hydrology.

In Table 3 are also reported the generic potentiality in using each reported feature. They range from (i) basic environmental information obtained by features such as flood, internal drainage, groundwater; (ii) direct data for inferring hydrological parameters (e.g. hydraulic properties parameters from organic carbon, texture and/or granulometry; modelling dissolved organic carbon concentrations and fluxes in catchments and streams from organic carbon content); (iii) occurrence of distinct water flow processes (e.g. preferential and/or bypass flow in presence of cracks; wet regime for the presence of a shallow water flow impeding horizon).

The central point is how such potentiality can actually be transferred in hydrological modelling. While the information of the point (i) are of general interest and those referring to the point (ii) easily and directly applicable, those referring to the point (iii) such as for instance the occurrence of iron mottles (indicating seasonal water stagnation) are not input parameters in any existing physically based hydrological models and therefore need a further explanation to better appraisal the potentiality embedded in soil map and database. In Table 4 we reported how some soil features can be fruitfully employed for conditioning hydrological models. In other words, we reported how distinguish some distinct water flow processes occurring in the soil without make specific hydrological test (e.g. infiltration, test with tracers). In this sense we act at the early stage of the modelling procedure in the definition of which processes (i.e. presence/absence of preferential flow) can (should) be simulated. Then we have defined this step as "conditioning of hydrological modelling" and the list of soil features to be used has been compiled considering a large bulk of literature attesting the relationship between these features and hydrology. Between these features we included living roots (Aubertin, 1971; Warner and Yong, 1991), macroporosity (Lin et al., 1999), mottles (Rabenhorst et al., 1998; Bouma et al., 1990), Fe and Mn concretions (Stoops and Eswaran, 1985; Hseu and Chen, 1996), colour of the matrix (Vepraskas, 2004), Fe and Mn coatings (Linbdo et al., 2010), clay coatings (Kuhn et al., 2010), carbonates coatings (Durand et al., 2010), gypsum coatings (Poch et al., 2010).

For example, the presence of the Fe concretions comes from alternating wet and dry condition. If they show a diffuse outline this means that a strong wet period may have occurred and therefore a fluctuating water table could be imposed as bottom boundary condition; other way, if they show an abrupt outline this means that a strong dry period has likely occurred and therefore the unit gradient can be imposed as bottom boundary condition.

Another case worth mentioning is the diffuse presence in the soil profile of coatings of manganese; they appear in soils having generally high soil moisture. In this case, the influence of the pressure head on the hydraulic gradient is reduced and therefore a simplified gravitational flow can be cautionary assumed.

The last example, taken from the Table 4a, concerns biological activity (observed in the field) and occurrence of slickensides; these features are completely different in their nature and genesis but both can produce macroporosity, potentially inducing preferential flow paths. In this situation a model at two pores domains (e.g. composite porosity approach, the double permeability approach) with or without an exchange term between the two domains should be applied. Furthermore, if the macroporosity produced by these two pedological features is anisotropic, a 2-D or 3-D domain of the flow field should be applied even in flat area where the lateral component of the gradient is generally discarded.

For all the above cited examples and for many others showed in Table 4a we have to remark that the given hydropedological indications are not real fluxes measurements. These indications can be used but they should take with caution crossing them with any other evidence, both pedological and hydrological, of occurrence of the same process; or they should be used to programming field campaign of fluxes measurements.

But despite these cautions, when using hydrological models in ungauged landscapes (such as in PUB), these features can indeed represent a great help in models conditioning.

A conclusive evaluation on the features given in Tables 2, 3 and 4 is required and it must emphasise the need for new methods/methodologies aiming to better quantify features described in the field. This need is not new and it is very much under development (e.g. Rossel et al., 2010) in the area of geophysics, geochemistry and spectroscopic analysis but indeed very little is available on soil hydrology. We believe that this area indeed deserves much more emphasis in soil science and it may enable a better interaction between soil science and hydrology.

\section{An application of pedological information to hydrological forecasting}

In the following we show some examples of interaction between pedology and hydrology toward hydrological forecasting. Unfortunately we do not have a single case study 
Table 4a. Indirectly usable soil features commonly occurring in databases and exploitable in hydrological modelling.

\begin{tabular}{|c|c|c|}
\hline Soil features & Simplified hydrological meaning of the soil features & Examples of modelling conditioning (1-D, 2-D, 3-D) \\
\hline Mottles & Alternating wet and dry condition with a strongly wet period & Bottom boundary condition: setting high fluctuating water table depth \\
\hline $\begin{array}{l}\text { Fe-Mn concretions } \\
\text { (abrupt outline) }\end{array}$ & Alternating wet and dry condition with a strongly dry period & $\begin{array}{l}\text { Bottom boundary condition: setting free drainage (hydraulic head } \\
\text { gradient }=-1 \text { ) }\end{array}$ \\
\hline $\begin{array}{l}\text { Fe-Mn concretions } \\
\text { (diffuse outline) }\end{array}$ & Alternating wet and dry condition with a strongly wet period & Bottom boundary condition: setting fluctuating water table depth \\
\hline $\begin{array}{l}\text { Greysh colour of } \\
\text { the soil matrix } \\
\text { (not lithochromic) }\end{array}$ & Strongly redox condition induced by water stagnation & Bottom boundary condition: setting low water table depth \\
\hline Clay coatings & Abundant water fluxes enable to be moved in macropores & $\begin{array}{l}\text { Use of preferential flow approaches (e.g. double permeability, } \\
\text { composite porosity, etc.). Occurrence of strong 2-D/3-D flow field } \\
\text { (not slope-induced) }\end{array}$ \\
\hline Fe coatings & Strongly redox condition induced by water stagnations & Bottom boundary condition: setting low water table depth \\
\hline Mn coatings & High moisture in soils & Simplified flow field during wet season (e.g. gravitational flow) \\
\hline $\mathrm{CaCO}_{3}$ coatings & $\begin{array}{l}\text { Alternating wet and dry condition with a strongly dry period } \\
\text { Stabilization of soil pores }\end{array}$ & $\begin{array}{l}\text { Bottom boundary condition: setting free drainage (hydraulic head } \\
\text { gradient }=-1 \text { ) }\end{array}$ \\
\hline Gypsum coatings & Very dry soil environment & $\begin{array}{l}\text { Bottom boundary condition: setting free drainage (hydraulic head } \\
\text { gradient }=-1 \text { ) }\end{array}$ \\
\hline $\begin{array}{l}\text { High biological } \\
\text { activity; high } \\
\text { frequency of } \\
\text { macropores and } \\
\text { living roots }\end{array}$ & $\begin{array}{l}\text { Presence of macropores and potential occurrence of preferential } \\
\text { flow paths }\end{array}$ & $\begin{array}{l}\text { Use of preferential flow approaches (e.g. double permeability, } \\
\text { composite porosity, etc.). Occurrence of strong 2-D/3-D flow field } \\
\text { (not slope-induced) }\end{array}$ \\
\hline Slickensides & $\begin{array}{l}\text { Strongly alternating wet and dry condition inducing preferential } \\
\text { flow paths }\end{array}$ & $\begin{array}{l}\text { Use of preferential flow approaches (e.g. double permeability approach, } \\
\text { composite porosity approach, etc.). Occurrence of strong 2-D/3-D flow } \\
\text { field (not slope-induced) }\end{array}$ \\
\hline High CEC & Filtering ability towards xenobiotics (especially if cationic) & $\begin{array}{l}\text { Setting of parameters for solute transport (e.g. retardation factor }>1 \text { in } \\
\text { convective-dispersive equation) }\end{array}$ \\
\hline $\begin{array}{l}\text { High andic } \\
\text { properties }\end{array}$ & $\begin{array}{l}\text { Filtering ability towards xenobiotics } \\
\text { High water retention and hydraulic conductivity }\end{array}$ & $\begin{array}{l}\text { Setting of parameters for solute transport (e.g. retardation factor }>1 \text { in } \\
\text { convective-dispersive equation). } \\
\text { Not applicability of standard PTF }\end{array}$ \\
\hline
\end{tabular}

Table 4b. Directly usable soil features commonly occurring in databases and exploitable in hydrological modelling.

\begin{tabular}{l}
\hline Soil features \\
\hline Horizon depth \\
Granulometry \\
Organic Carbon \\
Coarse fragments \\
Cracks \\
Electrical conductivity \\
\hline
\end{tabular}

including all the most important alternatives of interaction but case study 1 , which is devoted to a land evaluation exercise for maize production in a typical agro-ecosystem, it is an excellent methodological example to show the overall potential of applying hydropedology even in hydrology. We inserted other two case studies dealing with mapping of hydrological behaviour for irrigation planning and management at the district scale (case study 2) and flood event simulation in an ungauged basin (case study 3 ). The last case study was developed applying some novel data.
For the sake of paper readability we have reported in Appendix $\mathrm{C}$ some further details of the three case studies including a detailed description of the applied modelling.

Hereafter, after providing a short description of the case studies, we discuss their relevance for hydrology. This will also be performed following the synoptic scheme reported in Table 5. Here in the first column we report, in an increasing order, the crucial issue concerning which "soil map database is available" for each given case study (including sub-case studies). Then, sequentially, in the other columns we show (i) the questions we have been asked to answer, then from that basis (ii) what we have performed, (iii) the applied model, (iv) how and which hydropedological information have been employed to condition hydrological modelling, (v) what we have obtained, (vi) in general terms what we learn/get for hydrologic applications and finally and most importantly (vii) performance and costs of the given methods. 


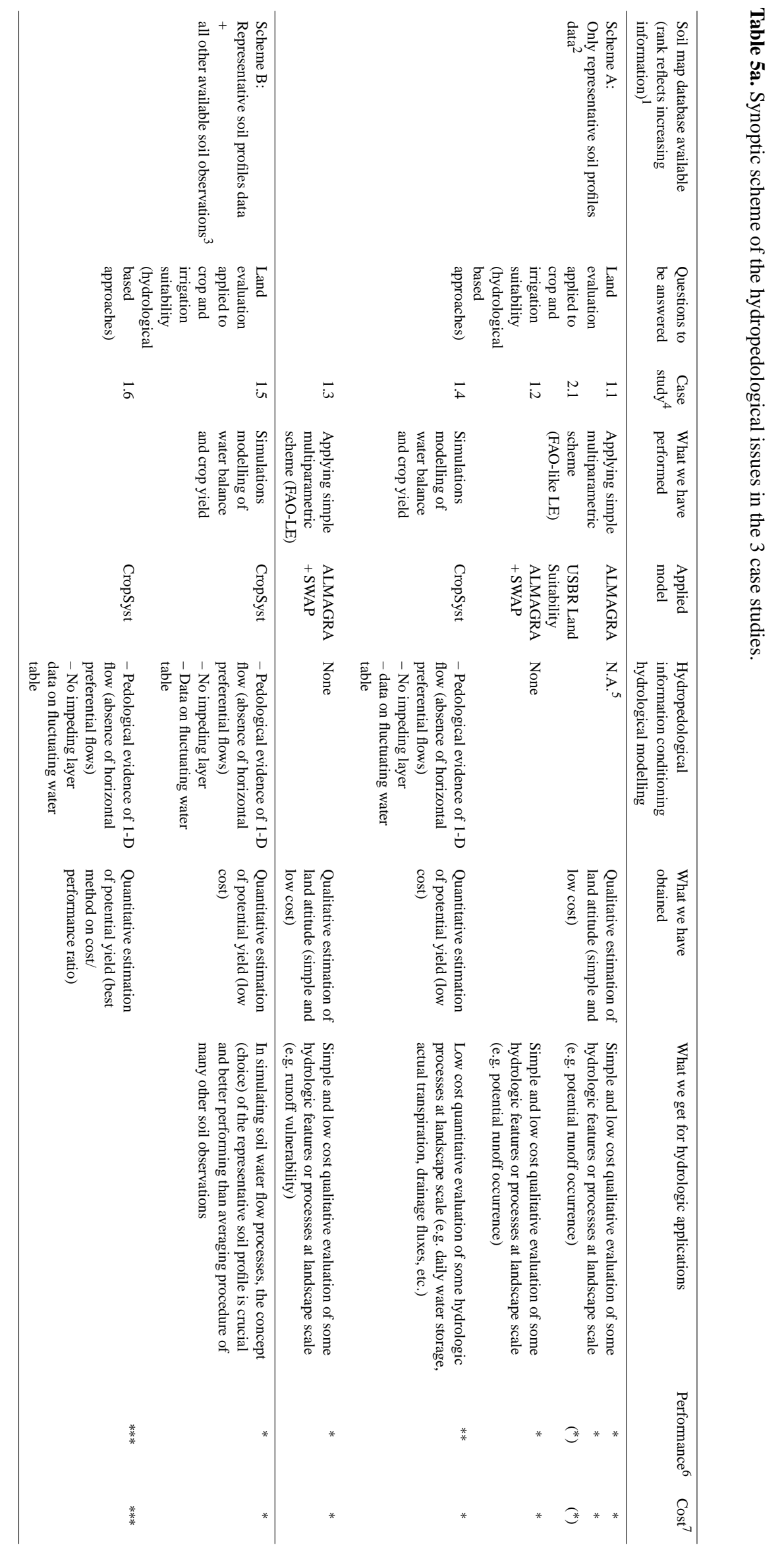



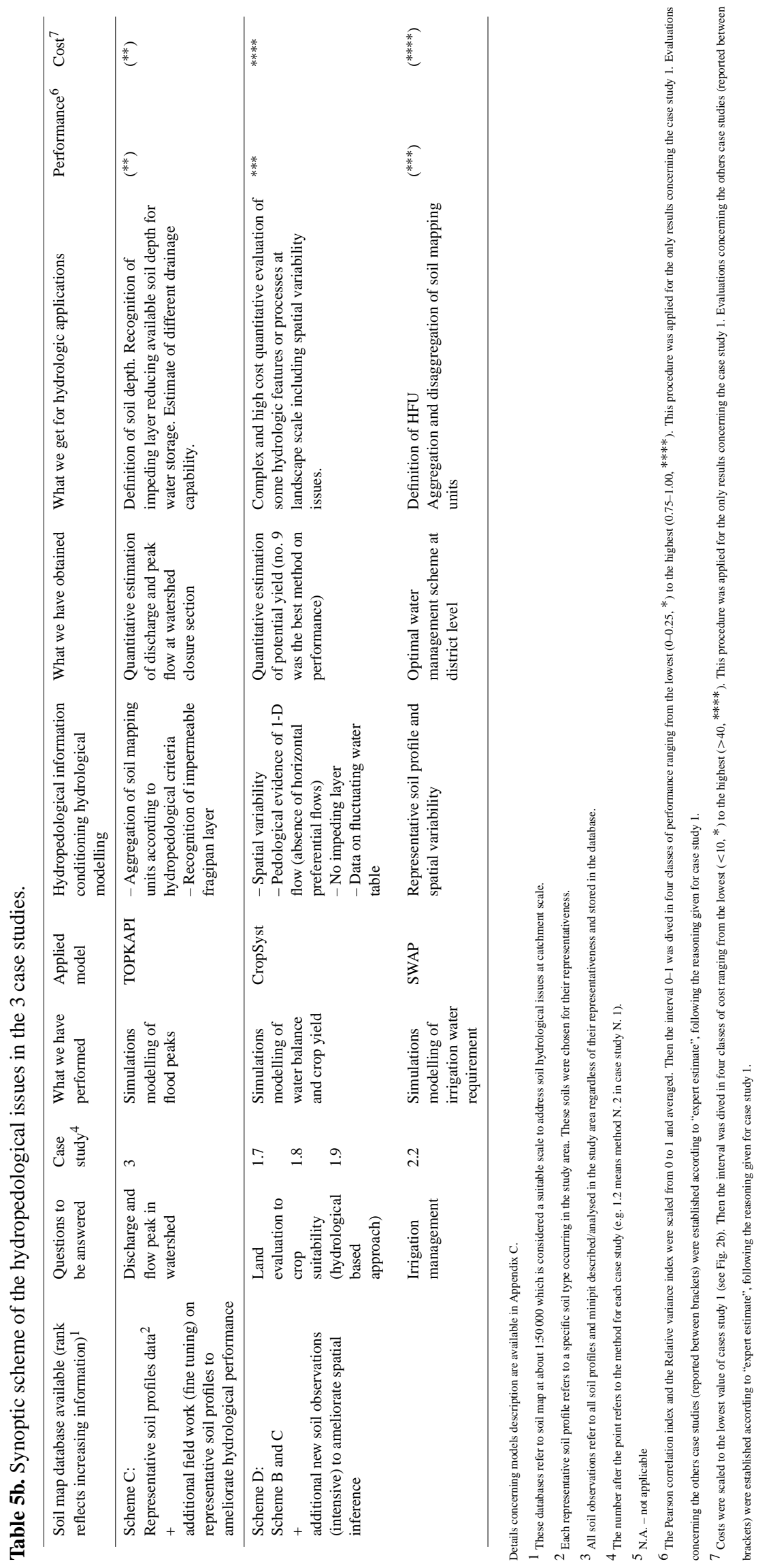


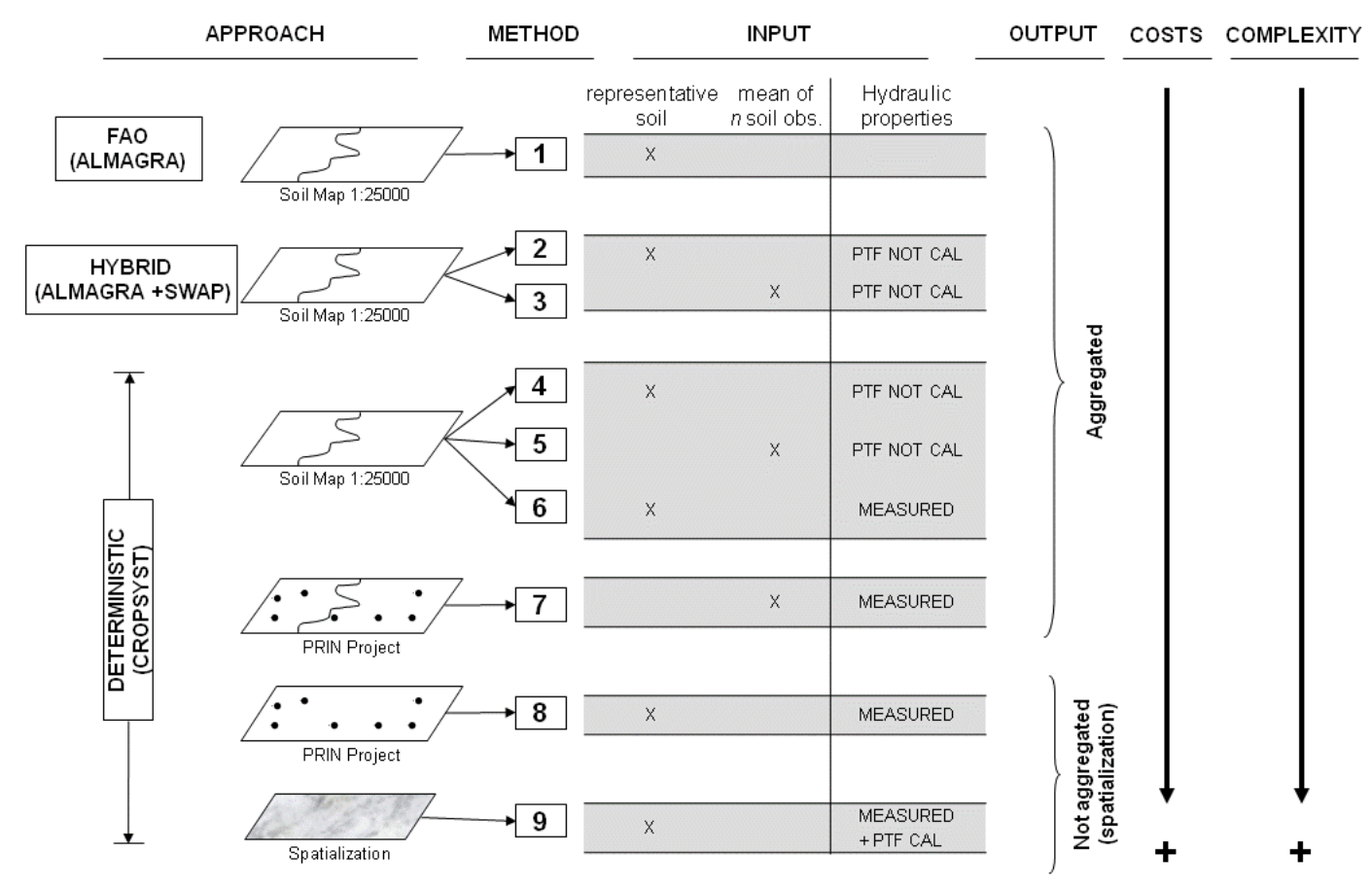

Fig. 1. Case study 1: approaches used and their main characteristics.

\subsection{Case studies}

\subsubsection{Comparative land evaluation models: from the FAO framework to simulation modelling}

Land Evaluation (FAO, 1976) is defined as "the process of assessment of land performance when used for specific purposes ...". The Land Evaluation models can be devoted to (i) agricultural and forestry productivity (land suitabilityrelated) and (ii) land use, planning and management for environmental protection (land vulnerability-related). In general Land Evaluation, normally based on morphological, (bio)physical and chemical data derived from soil survey, has been the most commonly used procedure worldwide to address local/regional/national land use planning; it works by using multi-criteria (many soil and land parameters) classification (matching tables, see Appendix C). Generally, this type of models are directly applied to soil map units then to single small and homogeneous area whose suitability or vulnerability is to be determined, without any information on spatial variability.

In the current example, elaborated after the paper of Manna et al. (2009) devoted to a land evaluation exercise for maize (forage) production in a typical agro-ecosystem (2000 ha in the Lodi plain, Po valley, Italy), we will show the overall potential of applying hydropedology in hydrology using nine alternative methods (Fig. 1) at increasing level of complexity. They ranged from a simpler standard land Evaluation approach (using ALMAGRA model, De La
Rosa et al., 2004) to a more extensive use of Richards' based simulation modelling (SWAP, van Dam et al., 1997 and CropSyst, Stöckle et al., 2003). For a brief summary of the main characteristic of the applied models see Appendix C.

Then we evaluated cost/benefit ratio of the different modelling approaches and then whether complex models (e.g. mechanistic simulation models) are really sustainable and appropriate for a specific landscape hydrological task.

We used as data input several information reflecting the 4 schemes reported in Table 5:

1. A pre-existing 1:50000 soil map with 22 soil units. The soil database is constituted by the only representative soil profiles data.

2. Soil database constituted by Scheme A (representative soils) and including all soil profiles and minipit described/analysed in the study area regardless of their representativeness.

3. An additional hydrology-oriented and limited field work (fine-tuning) was carried out on the only representative soil profiles and laboratory measurements of water retention (Dane and Hopmans, 2002) and saturated hydraulic conductivity (Reynolds et al., 2002) were performed.

4. A further additional intensive hydrology-oriented field work of 100 sites located after a stochastic spatial simulation annealing procedure (Aarts and Korst, 1989). 
This procedure was performed on the basis of preexisting soil map, geological data and reference soil profiles data. The corresponding data set include particle size distribution and main chemical parameters (e.g. pH, EC, OC, etc.).

On 50 of these 100 supplementary sites bulk density, water retention curve (Dane and Hopmans, 2002) and saturated hydraulic conductivity (Reynolds et al., 2002) were measured. In the remaining 50 supplementary sites, water retention was estimated by the PTF of Vereecken et al. (1989) and saturated hydraulic conductivity by the HYPRES PTF (Wösten et al., 1998).

For modelling purposes, data on groundwater level (lower boundary conditions) were obtained from a monitoring site (Bonfante et al., 2010) and from the soil map report. Daily climatic data were obtained from the meteorological monitoring network of Regione Lombardia (ARPA Lombardia http://www.arpalombardia.it).

An independently estimate data set of maize green biomass was used to test the results of the different models; it was obtained from the relationship $\left(R^{2}=0.83\right)$ between NDVI images (several 16-days based MODIS VI, $250 \times 250 \mathrm{~m}$; one visible and near IR QUICKBIRD, $2.4 \times 2.4 \mathrm{~m}$ ) and 10 green biomass measurements at ground (Manna et al., 2009).

The comparison between the different methods is based on both cost and "predictive performance", defined as the ability of a specific method to successfully discriminate areas with different forage maize suitability. All the output estimates of the nine methods were expressed as suitability classes with respect to the production of maize biomass. The predictive ability was derived using different statistical indexes including (i) the Pearson correlation coefficient $(r)$ to express the degree of existence of a relationship and (ii) the relative variance $\left(1-V_{\mathrm{cl}} / V_{\text {tot }}\right)$, given from the complement to 1 of the ratio between within-class and total variance, to express the success of the classification in reducing the variance within classes.

In Fig. 2a are shown these statistical indexes vs. land Evaluation methods where the higher is the value the better is the predictive performance. In Fig. $2 b$ is given the final cost per unit area, normalized with respect to the less expensive method.

Scheme A deals with the first given example of Table 5 and it shows the case of having a soil map with the only representative soil profiles data and without any additional associated data or hydropedological information to condition hydrological modelling. The outcoming results using a classical Land Evaluation approach - methods 1.1 and 1.2 - are very poor over all the Land Evaluation performance indexes, but indeed these poor results are associated to a very low budget investment (Fig. 2 and last two columns of Table 5). These findings confirm that the worldwide multicriteria FAO-like Land Evaluation approaches best perform at regional scale rather than the detailed scale such as our case study. Despite these results, a coarse hydrologic benefit can still be represented by the simple and low cost qualitative evaluation of some hydrologic features or processes at inventory scale. For example, a simple scheme of Land Evaluation using available data as texture, presence of impeding layers, structure, depth of the profile, morphology, etc. can indeed provide, at the inventory scale, qualitative soil suitability towards potential runoff occurrence.

In Scheme A a good alternative to the classical Land Evaluation can be represented by the method 1.4. Here the only soil information is still the soil map database based on representative profiles; but we have applied a physically based model of water balance and crop yield (CropSyst, see Appendix C). In this case a quantitative estimation of potential yield is then obtained and the leap in the predictive performance is evident despite the correlation remain low (Fig. 2a). The good results of the method 1.4 may be explained by some hydropedological evidences applied in conditioning hydrological modelling. Those evidences were based on the following: (i) the rather homogeneous geomorphologic setting consisting in an alluvial plain (but still having two very distinct terracing systems) may have made the 1-D water flow assumption feasible, especially considering the absence of pedological evidences of horizontal preferential flows (e.g. no cracks, no slickensides, very limited occurrence of clay and silt coatings, etc.); (ii) the latter, coupled with no evidence of compacted soil horizons (e.g. iron pan, fragipan, etc.), enabled a more confident applicability of standard PTFs that could easily failed in presence of such features. In fact, despite many PTFs try to take into account the soil structure through the bulk density, this is very often estimated by another PTF (Rawls, 1983) and not directly measured, especially in deeper horizon where, unfortunately for the applicability of PTFs, the occurrence of compacted layers is both more frequent and more difficult to get an undisturbed soil sample. Finally, (iii) the soil map has also some information on fluctuating water table permitting a better definition of the bottom boundary condition.

Therefore, in analogy to methods 1.1 and 1.2, this method can be beneficially applied also to coarse hydrology applications. For example, a rather inexpensive quantitative evaluation of some hydrologic processes at landscape scale accounting for large hydrological difference between soils (e.g. daily water storage, actual transpiration, drainage fluxes, etc.) can be easily applied, through the application of a 1-D Richards based model.

The Scheme B concerns those case studies (methods) having in addition to Scheme A (soil map database including the only representative soil profile data) an associated database including all other existing soil observations. In this case no improvement was observed after applying averaging procedure (method 1.2 vs. 1.3 and method 1.4 vs. 1.5 , respectively) of the soil observations (see Table 5 and Fig. 2a), in agreement with the findings of Heuvelink and Pebesma (1999) 

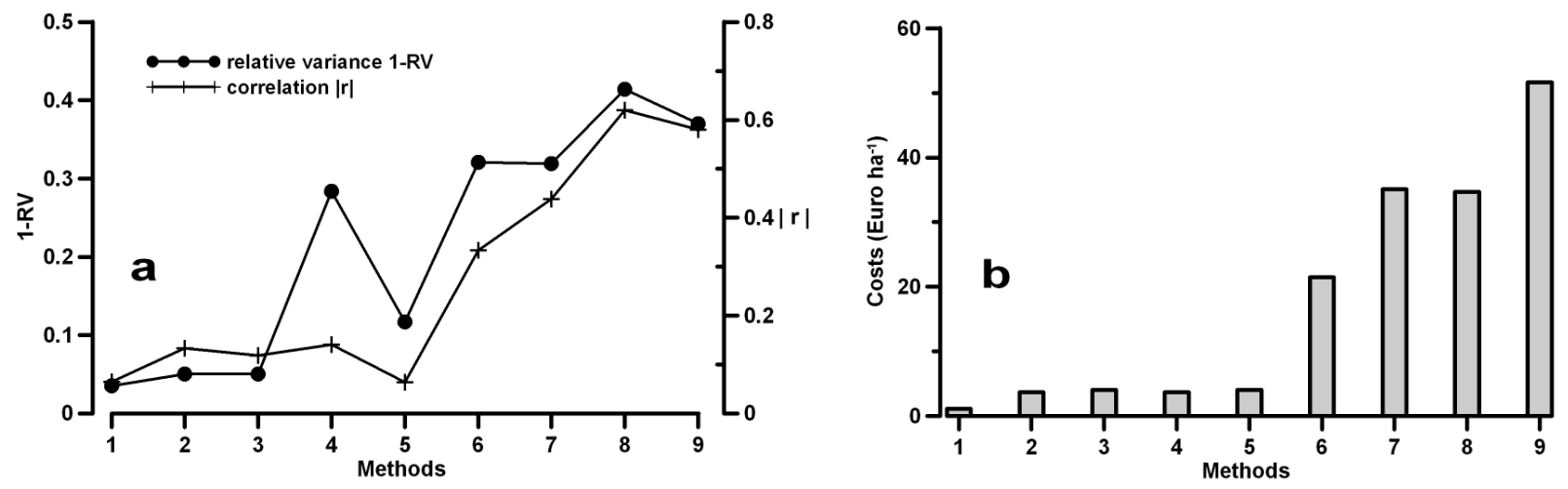

Fig. 2. Case study 1: performance indexes and costs of the tested LE methods in relation to the level of complexity.

concerning the importance of working on real soils and on real measured data rather than processing or averaging observations of several different soils.

Scheme $\mathrm{C}$ concerns those case studies having the only soil map database of representative soils integrated by an additional fine tuning consisting of an extra field and laboratory work to obtain measured soil hydraulic properties. Models have been conditioned by hydropedological appraisal as reported for the Scheme A. Method 1.6, is the one showing all good performance indexes at the lowest cost (but still 19fold higher than method 1.1). Particularly, it shows a correlation twofold higher than method 1.4 (Fig. 2a) despite the two methods differ by the only hydraulic properties (measured vs. estimated by PTF). In terms of hydrologic application, we can deduce from these findings that in simulating soil water flow processes, the concept (choice) of the representative soil profile, especially if hydrologically characterized, is crucial and better performing than averaging procedure of many new soil observations. Thus, strictly speaking, this method is the lowest cost method to be chosen, producing consistent results.

As expected the best prediction results were obtained after abandoning the support of the soil-mapping units, strikingly increasing the number of samplings and analyses and eventually performing geostatistical analysis (Method 1.9, Scheme D) as in the case of digital soil mapping processing (Fig. A1). Needless to say, this approach was 47 times more costly than standard Land Evaluation approaches (Fig. 2b) and poses major questions on its sustainability. Here we must emphasise that this last approach is similar to a large bulk of scientific literature (e.g. Western et al., 1999; Grayson and Blöschl, 2000; Lyon et al., 2006) proving the importance of incorporating spatial variability issues in hydrological applications discharging any evaluation concerning cost benefit ratio.

Summing up, comparison between the Land Evaluation (FAO) framework and mechanistic simulation modelling disproved the assumption that an increase in model mechanics and complexity always means an increase in its predictive ability. Indeed, in this case study, the predictive ability evolves discontinuously with respect to model complexity. Data quality is indeed the leading parameter affecting the performance of land evaluation and also plays a major role in determining final costs.

Our findings, being largely based on detailed characterization of soil hydropedological behaviour, show great potential also in other hydrological-based applications. This is the case for instance when addressing environmentally related topics (e.g. groundwater vulnerability, nitrate pollution, rainfall-runoff processes, etc.) where soil functions such as storing, filtering, transformation and interface for runoff generation are important.

\subsubsection{Mapping of soil hydrological behaviour for irrigation management}

One typical issue in landscape hydrology applied to agriculture is both the planning and management of irrigation at the district scale (which are typically smaller than $10^{4} \mathrm{ha}$ ). This is traditionally achieved by using soil information to derive in a simplistic way the land suitability classes for irrigation (USBR, 1981 and Appendix C). The purpose of this suitability approach is to assess whether a soil has an inherent capacity to pay off both the overall investment plan of the hydraulic system for irrigation and to provide appropriate added value to farmers.

A case study in Sardinia (Arangino et al., 1986) can help in appreciating this procedure. More specifically an irrigation capability class was assigned to each soil mapping unit using the soil map information. Parameters employed for performing such assignment were both qualitative (i.e. drainage class, degree of mineral weathering, risk of soil erosion, etc.) and quantitative (i.e. slope, stoniness, rockiness, clay content, salinity, carbonates, profile depth). These parameters were combined into an empirical multiparameter scheme (Appendix C) in order to produce a soil suitability map for irrigation. Then this suitability has been employed to review all areas included in the project and also to identify new areas suitable for irrigation. 

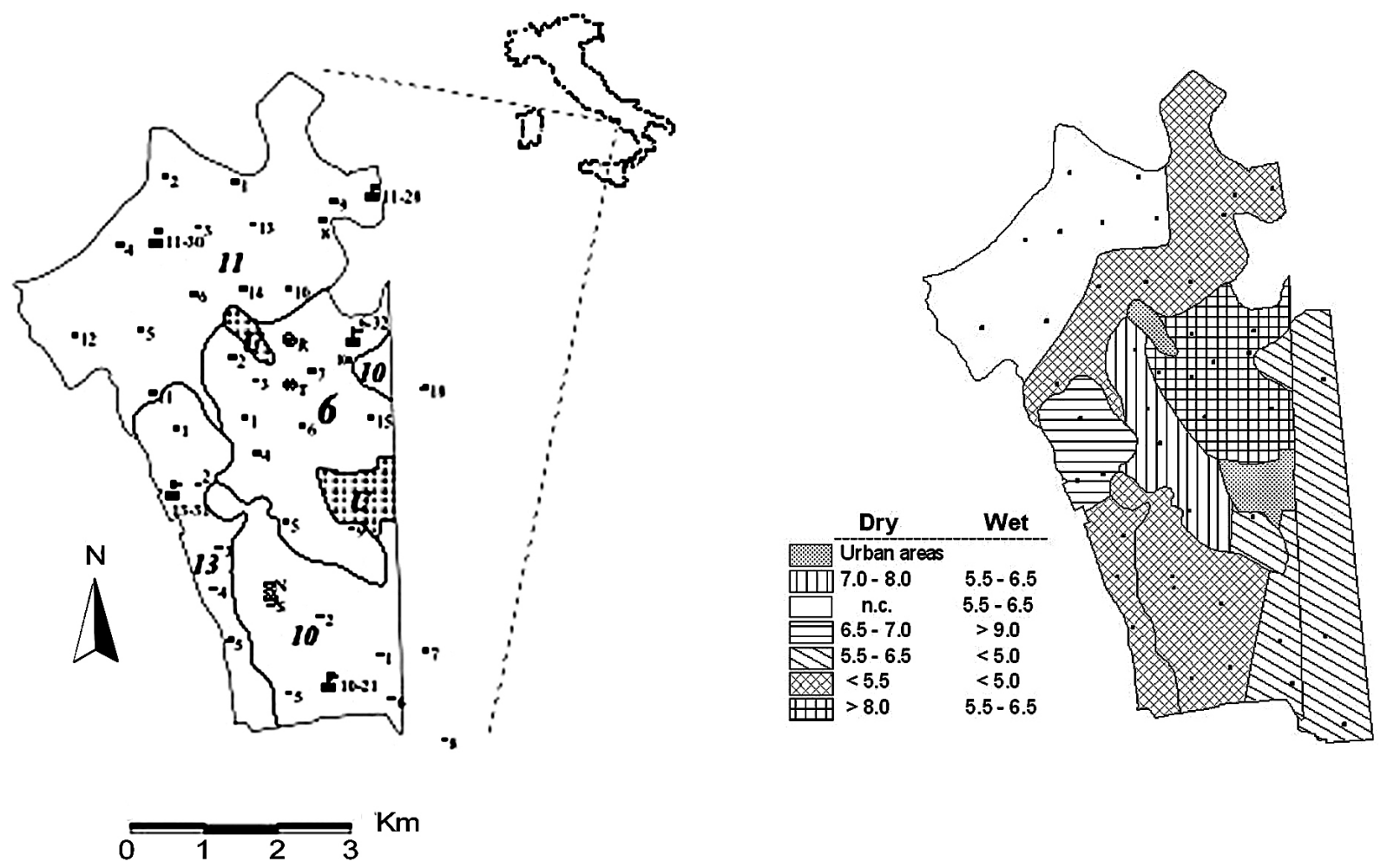

Fig. 3. Case study 2: (a) soil map and (b) hydrological functional units classified on the basis of the "functional property" $d_{800}$.

This approach is a kind of land evaluation and it has been largely employed in different parts of the world to address local/regional/national land use planning. Despite its widespread use, the scientific community has largely criticized the procedure for its qualitative and empirical basis and therefore we can consider that both disadvantages (qualitative and crude approach) and advantages (simple and lowcost qualitative evaluation of some hydrologic features or processes at inventory scale) are the same given for the case study 1.1 in Scheme A (Table 5).

In order to achieve a better irrigation management and departing from this scheme, we have performed a further step taking into account the inherent soil spatial variability within each soil unit, especially of those soil properties largely influencing the soil water balance, such as water retention and hydraulic conductivity.

We have applied physically based numerical models, which are known to be a valuable tool to simulate soil water flow, yielding the soil-vegetation-atmosphere water balance. In particular these algorithms, once calibrated and validated to the specific conditions of a study site, can be used to improve the efficiency of irrigation, thus contributing to the rational use of water resources (Bonfante et al., 2010).

Unfortunately, the application of these models at the landscape scale is strongly limited by the availability of spatially variable information for a correct description of the soil hydraulic behaviour. By coupling pedological information, as already available in a soil map, and a small number of hydrological analyses, D'Urso and Basile (1997) proposed a method to classify soils according to their hydrological behaviour in an earlier application of the Hydropedological Functional Unit concept, and falling in the case in Scheme D of Table 5.

The main points of the procedure were as follows:

- identification of the representative soil profile within each soil mapping unit;

- additional field work on each soil horizon of the representative soil profiles for the characterization of the hydraulic properties (namely, $\theta(h)$ and $k(\theta)$ functions) and particle-size distribution;

- calibration of a specific soil unit quasi physically-based PTF (Arya and Paris, 1981), through coupling the measured hydraulic properties and the particle size distributions (Basile and D'Urso, 1997);

- additional new soil observations for application of the calibrated PTFs to several points in the whole area;

- definition of a specific "functional property" (i.e. $d_{800}$, the time interval between two optimal irrigation from the output of the simulation model) and application of the SWAP model (Appendix C) in all the sampled soils; 
- aggregation and disaggregation of soil units by a new classification of soils on the basis of the "functional property" and demarcation of new units hydrologically homogeneous (HFUs).

The method was developed on an $11 \mathrm{~km}^{2}$ river plain serviced by the Sinistra Sele Irrigation Consortium (southern Italy); an irrigated area where a soil map was already available (Fig. 3a). The drainage process following irrigation was simulated by SWAP a Richard's based 1-D model (Appendix C) and the chosen output was the "functional property" $d_{800}$, defined as the number of days required to reach an average pressure head of $-800 \mathrm{~cm}$ in the soil layer between $10 \mathrm{~cm}$ and $30 \mathrm{~cm}$ depth. The value of $-800 \mathrm{~cm}$ is the soil pressure head at which stress starts in the chosen crop (alfalfa) and therefore the calculated "functional property" represents the optimal interval between two irrigations in the event of on demand irrigation supply. The functional property $d_{800}$ ranges from a minimum of 4 to a maximum of 8 days. The soil classification map shown in Fig. 3a was modified to account for the hydrological similarities highlighted by evaluating $d_{800}$. The new classification allows production of the HFU map shown in Fig. 3b. Specifically, some soil mapping units were disaggregated; for example the soil mapping unit n. 11 (Fig. 3a) was divided in two sub areas, the lower with $d_{800}<5.5$ with a short interval time between two irrigations appears from rather draining soils while, the upper one, close to the Sele river, was not classified (n.c.) because of the high variability at the investigation scale. Others were aggregates; for example part of the soil mapping units 10 and 6 (Fig. 3b) merged in the same HFU $\left(d_{800}<5.5\right)$.

This new classification was the basis of several papers devoted to optimal water management (D'Urso and Minacapilli, 2006; Bastiaanssen et al., 2007).

It is useful to emphasise that this approach shows the large flexibility in using HFUs; in fact once the procedure has been adopted to perform a specific task (in our case the $d_{800}$ functional property), very little adjunctive work is needed for addressing new tasks requiring for instance new (purpose driven) functional properties and maps.

\subsubsection{Flood event simulation in an ungauged basin: the contribution of soil data}

In the Sangone basin (NW of Italy) the only data available refer to the meteorological and discharge time series at the closure section. This basin of about $150 \mathrm{~km}^{2}$ shows considerable pedological and hydrological complexity. It is formed by three main geomorphologic systems: mountain ridges, slopes at different gradients and aspects, and valleys. The main question we addressed is to what extent a parsimonious identification of soils (forms) can help in interpreting the hydrological complexity hidden in flood forecasting (functions).

The study was performed through a comparison of the results obtained by using TOPKAPI, a physically based distributed model of infiltration-runoff processes with parsimonious parameterization (see Appendix C), applying blind (i.e. without any calibration) simulations relative to two different levels of soil knowledge, namely: (i) soil characteristics retrieved after a global soil map resource, (ii) soil characteristics derived after a (parsimonious) soil survey campaign. The soils were accordingly parameterized relative to the different approaches.

The approach with the most basic level of knowledge (Scheme A in Table 5) employed as dataset of soil types the FAO/UNESCO Soil Map of the World. This dataset was developed under the SOTER Programme and the old FAO legend was replaced by the update World Reference Base for Soil Resources (WRB, 2006). This dataset includes 106 soil units of which four are in the study area, based on Zobler's assessment of the FAO/UNESCO Soil Map of the World. Soil properties such as soil depth and saturated hydraulic conductivity are derived for each soil type from the FAO-UNESCO soil classification. The soil hydraulic properties, i.e. water retention and unsaturated hydraulic conductivity, represented by van Genuchten's - Mualem formulas (van Genuchten, 1980) are estimated by PTF. This dataset clearly has the limitation of a coarse resolution and of qualitative information on the soil characteristics. However, it is representative of the minimum level of knowledge available for the implementation of a hydrological model. Moreover, the dataset was also used in several applications (Doll et al., 2003; Liu et al., 2008) where other (local) sources of data were not available.

The second approach (soil hydrology driven) having a higher demanding level of knowledge (Scheme $\mathrm{C}$ in Table 5) consisted of the following main steps:

1. A preliminary study of pre-existing available information (soil use map, 1:250000 soil map, 1:50000 soil map available for the only lower plain area, 1:50000 geological map, 1:10000 DTM).

2. A synopsis and definition of preliminary soil mapping units obtained, along with standard thematic layers (e.g. geology, land use, etc.), using some environmental covariates data. They resulted, from a pedological viewpoint, very useful for describing the specific soil distribution of the study area. Between them, we include a fuzzy c-means clustering to classify the DEM (de Bruin and Stein, 1998), and a study of vegetation by analysing the NDVI (Normalized Difference Vegetation Index) using Landsat and Modis images (Rouse et al., 1973; Tucker and Sellers, 1986; Wang et al., 2004).

3. A soil survey mainly limited to describe and to sample supposedly "representative soil profiles" inside each identified preliminary soil mapping unit (about 50 soil profiles and 50 minipits). The choice of representative soils is indeed crucial (and questionable) in this procedure; but at the present day we do not think that there are 
better "sustainable" options to the use of a traditional pedological understanding (CLORPT).

4. Soil chemical analysis on about 220 soil samples $(\mathrm{pH}$ in $\mathrm{H}_{2} \mathrm{O}$, $\mathrm{pH}$ in $\mathrm{KCl}, \mathrm{pH}$ in $\mathrm{NaF}, \mathrm{EC}, \mathrm{OC}, \mathrm{CEC}, \mathrm{EB}$, and then $\mathrm{Fe}, \mathrm{Al}$ and $\mathrm{Si}$ extracted in oxalate at $\mathrm{pH}=3$ ).

5. A synopsis of all acquired data and definition of a schematic soil map having 19 soil mapping units. It must be emphasised that this soil map produced from point 1 to 5 is named "schematic" because has much less soil observations (and then lower costs) than those required by standard soil maps (Appendix A).

Points 1 to 5 refer to the specific contribution of pedology to discriminate the forms (Lin et al., 2008) of the area.

6. The use of TOPKAPI model (as many other hydrological models) for an application in PUB where nor observed neither gauged internal data are available in order to simplify the input dataset and then to aggregate the 19 soil mapping units into a fewer number mapping units. This point is crucial both from an hydrological point of view since it requires the use of parsimonious but efficient models and from an hydropedological point of view because it requires an aggregation of mapping units having, potentially, a similar hydrological behaviour. This has been performed using the hydropedological reasoning given in Table 4. Therefore the original 19 soil mapping units were aggregated to form 8 mapping units named here as "soillandscape" units, because strongly based on the landscape features (Table 6). For instance this has been the case for four soil mapping units referring to "ancient fluvio-glacial deposits, erosional slope of river terrace, moraine steep slope, moraine crest" aggregated into the new soil-landscape mapping unit "ancient fluvioglacial deposits". In this case aggregation was ruled by the occurrence of a flow impeding soil layer (fragipan horizon) at shallow depth in very deep soils. Then in this soil-landscape unit the soil water balance is mainly driven by this fragipan horizon rather than soil hydrological properties and/or soil depth.

7. Determination of soil hydraulic properties at the eight soil-landscape units. In some stony soils and thin horizons, water retention and hydraulic conductivity curves were determined through an inverse method following a process of infiltration at predefined pressure heads (Šimunek et al., 1998). Undisturbed soil samples were analysed in the laboratory by applying the fallow head method (Reynolds et al., 2002) for the saturated hydraulic conductivity, Wind's method (Arya, 2002) for the unsaturated hydraulic conductivity and the wet branch of the soil water retention curve, and the WP4-T method (Bittelli and Flury, 2009) for the dry branch of the soil water retention curve. Data were parameterized according to the constitutive functional relationships of the TOPKAPI model.

8. TOPKAPI model requires a single set of parameters for each soil profile, assuming a substantial homogeneity along the soil profile. The consequent problem of identifying an effective set of hydraulic properties for an equivalent fictitious single-layered soil profile, giving the same hydrological response as the real layered soil, was solved as follow: for each soil profile a 1-D simulation by means of Richards'-based Hydrus model (Šimnek et al., 2008; see also Appendix C) was performed describing the profile according to the genetic horizons each one with own measured hydraulic properties (point 7). Then an inverse estimation procedure was applied assuming the profile as just one single horizon; the mean of each parameter along the profile was assumed as initial estimate and the water storage, $W(t)$, coming out from the multilayer simulation was used as "measured" hydrological response to be matched by the one-layer simulation. Under the same boundary conditions the equivalent homogeneous medium will have the same amount of stored water as the heterogeneous one. It follows then the hydraulic functions obtained for this equivalent homogeneous medium are the effective hydraulic functions of the heterogeneous medium. This approach has been largely adopted in the literature (among others: Yeh, 1989; Jhorar et al., 2004).

In the Fig. $4 a$ and $b$ the results of the comparison of the simulations of the FAO soil map against those referring to the soil-landscape units are shown. As can be easily seen, simulation from the first approach using the FAO soil map reproduces none of the important features of the hydrograph such as peak flow, the rising and recession limb. Differently, simulation from the second approach, which exploits the soil data collected in the field and the classification, is able to reproduce such features. The importance of the soil properties, which most affect the simulation performance, can also be recognized. The peak of the discharge is meaningful of the runoff mechanism. In the first parameter set, the soil is shallow and with low permeability. The runoff volume is then overestimated because the soil capacity is exceeded in much of the catchment and the volume infiltrated into the soil is very low. In the second parameter set, the soil distribution is more accurate, enabling a distinction to be made between the hillslope, with a shallow soil, and the valley, with deep, permeable soils. The peak flow is correctly estimated, which means that also the runoff mechanism is captured.

The recession limb of the hydrograph is strongly connected with the baseflow. In the first approach the baseflow is underestimated since the transmissivity of the soils, especially those beside the river, is not correctly parameterized. In the second approach the slope of the hydrograph is very similar to that observed. An important role here is played 


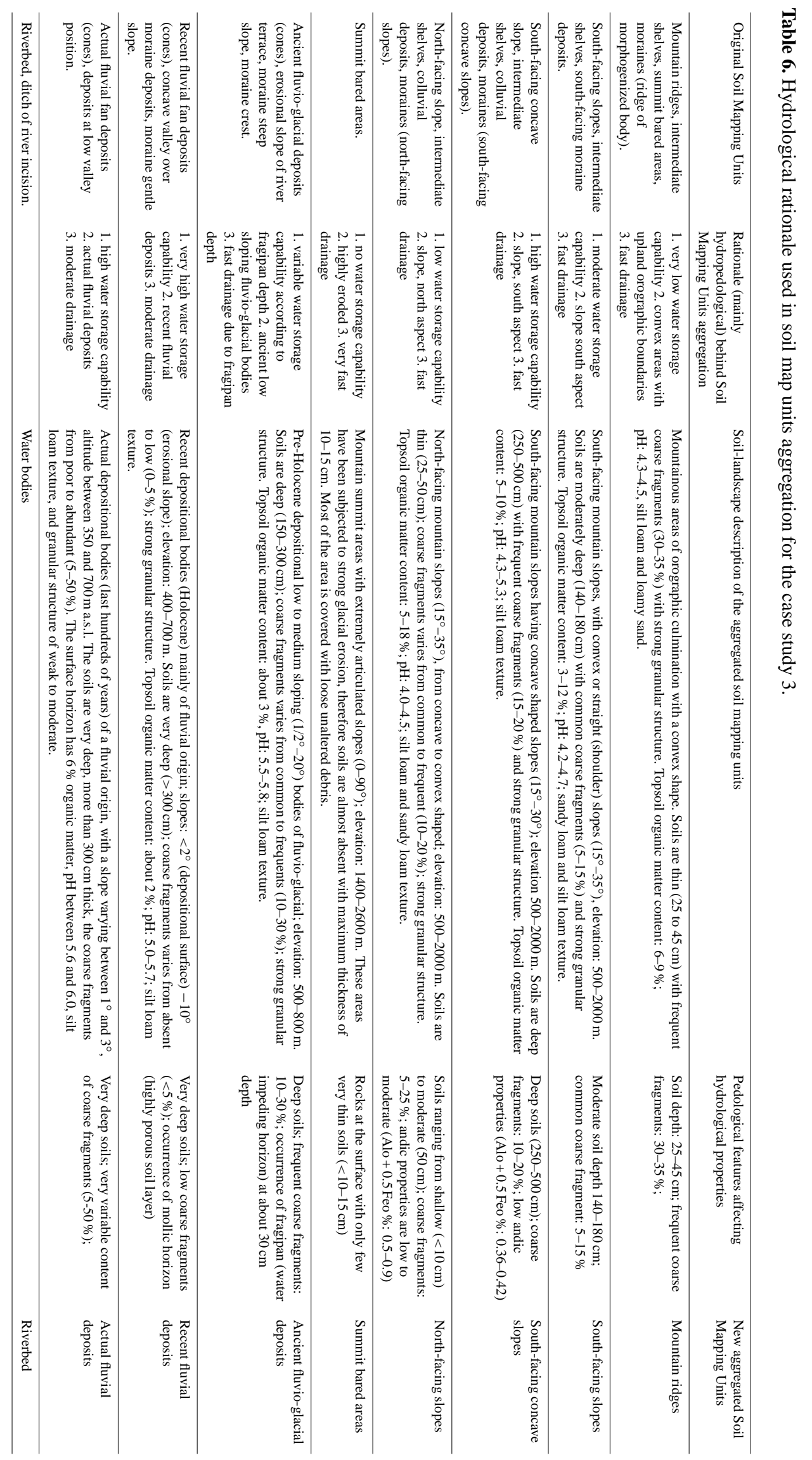



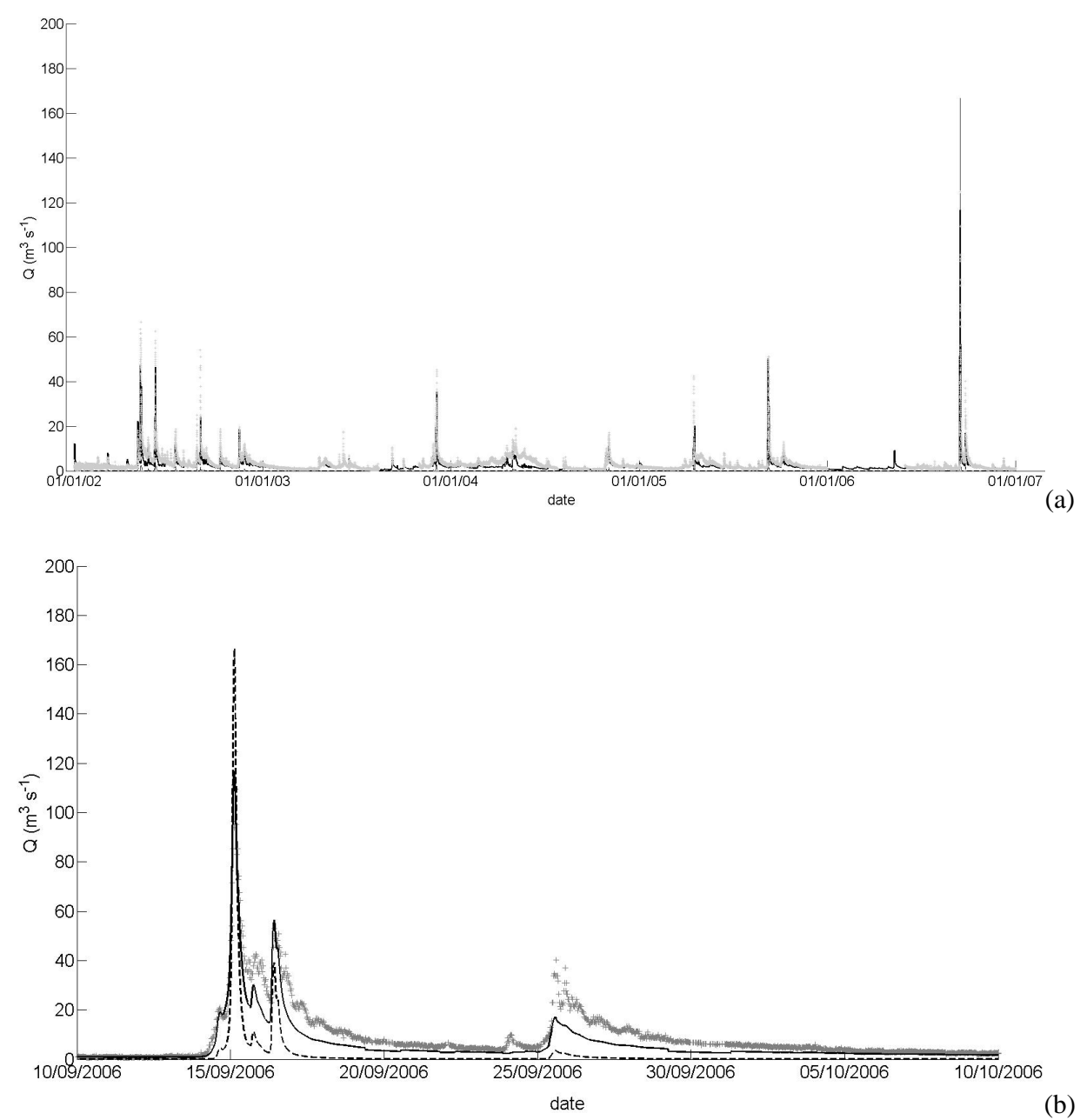

Fig. 4. Case study 3: hydrographs of the Sangone catchment (a) from January 2002 to September 2007, and (b) at the main flood event in September 2006. Symbols (+) are the observed discharge, dashed line is the simulation using the FAO dataset and black line is the simulation using the soil-landscape data set.

Table 7. Statistical indexes of the simulated discharge applying FAO and soil-landscape map.

\begin{tabular}{lrc}
\hline Parameter & $\begin{array}{r}\text { FAO } \\
\text { soil } \\
\text { map }\end{array}$ & $\begin{array}{c}\text { Soil- } \\
\text { landscape } \\
\text { unit } \\
\text { map }\end{array}$ \\
\hline Nash-Sutcliffe coefficient & 0.21 & 0.89 \\
RMSE $\left(\mathrm{m}^{3} \mathrm{~s}^{-1}\right)$ & 14.68 & 6.58 \\
\hline
\end{tabular}

by the soils in the deposit (downstream) that, according to the parameterization, have a high transmissivity (relative soil thickness and permeability) such that the low flow is also captured.

In Table 7 are given the computed Nash-Sutcliffe (NS) and the Root Mean Square Error (RMSE) coefficients aiming to assess the overall simulation performance. Both the NS and the RMSE show a clear improvement of the model performance when the soil-landscape map is applied. Particularly the NS coefficient, which is more hydrologically based, show a large increase since both peaks and baseflow are better captured by the soil-landscape unit map rather than the FAO UNESCO soil map.

The (expected) different performance between approaches measures the improved knowledge gained by just using the information coming from the landscape soil mapping units classification. The FAO soil map is taken here as the "null hypothesis" of the knowledge which one could eventually get, while the landscape soil map proposed may be thought as the minimum sustainable compromise for more realistic model predictions. In other words if one should use a model without a specific campaign to collect or elaborate hard data, its level of knowledge it not "nothing", but - without any efforts - "something" i.e. those information already available. With this level of knowledge any improvements should be compared to measure its adding value. 


\section{Conclusions}

The importance of knowing the soil distribution (forms) and processes (functions), which determines a sort of physical signature of the catchment, becomes very important when making hydrological predictions in the absence of hydrological monitoring data (such as in ungauged basins). Attempting to make the interaction between hydrology and soil effective - also in terms of catchment classification - this paper aimed to explore potential and limitations of soil survey and soil mapping. This aim has been performed by analysing the quality and quantity of information embedded in soil map and illustrated hydropedological analysis applied in three case studies from Italy (i.e. comparative land evaluation modelling, mapping of soil hydrological behaviour for irrigation management at district scale, and flood event simulation in an ungauged basin). Eventually we showed that data from soil survey have lots to offer but also that special care is required in handling soil database data if their full hydrological potential is to be achieved.

Regardless the diverse and specific outcomes of each of these case studies some common key hydrological points must be risen:

\section{i. The complexity of the model to be applied}

Very simple and widely applied models such as the Land Evaluation (LE) procedure has been widely criticized by the scientific community for its qualitative and empirical basis which makes it difficult to successfully address many new soil-(agro-)environmental challenges which indeed require the dynamic characterization of the interrelated physical and chemical processes taking place in the soil landscape.

On the other hand, many theoretically problems in the hydrological application of physically based model (e.g. physics of heterogeneity, equations and parameters scale integration, etc.) are still unsolved, despite they where posed many years ago (Beven, 1989).

Moving between these two extreme approaches, albeit not linearly, increasing model complexity and hence the accuracy of the described phenomenon requires an increase in basic data parameters and thus generates higher costs. This is even more important in ungauged basins where the lack of data is a crucial factor towards the proper modelling choice, according to "the right results for the right reasons" statement (Grayson and Blöschl, 2000). In this respect, this paper support that a generalization of the methodological pathway from simple to complex modelling application in a land evaluation procedure for maize production (case study 1) can be extended to landscape hydrology issues. It was proven that, for this case study, the Richards' equation could be effectively applied also at landscape scale. This finding was tested also for others case studies, where indirectly (case study 2) or through simple catchment response (case study 3 ) we evaluated the goodness in using physically based model at the landscape scale.

These good results may also be ascribed to

ii. the good choice in selecting representative soil profiles followed by their hydrological characterization

This was particularly true in the case study 3 , characterised by a limited dataset of hydrological measurements. It was demonstrated the effectiveness of a hydrology-devoted and relatively inexpensive soil survey (with respect to standard soil survey approaches) only aiming to identify the main soil mapping units and to select few representative soil profiles where to produce a soil hydraulic characterization. In general terms, it must be emphasised that both the identification of soil mapping units and the selection of representative soils is more difficult in an alluvial plain settings rather than in typical upper catchment landscape where both topography and soil outcrops better assist these critical choices made by the pedologist.

The other crucial issue, regardless the representativeness of specific soils, is indeed the complex problem of soil heterogeneities, typically addressed through a spatial analysis taking into account intra-unit spatial variability of hydraulic properties.

To this respect, a simple widely used approach is

iii. the spatial analysis of soil hydraulic characteristics (parameters) through PTFs.

This lead to assume that the spatial variability of texture and soil pore architecture (e.g. pore size distribution, pore connectivity, water retention, hydraulic conductivity) are similar. This assumption can be rather controversial considering the different underlying physics governing soil particles and soil pores, notwithstanding a large bulk of literature on PTFs use is based on it. To this respect, in case study 1 we showed that the heterogeneity was better described, in terms of statistics and spatial pattern, by real measurements of hydraulic properties than those estimated by PTF. The issue has been further explored in the case study 2 where a quasi physically-based PTF was calibrated for each soil mapping unit; in this specific case the inter-unit uncertainty was taken on board by the representative soil profile hydraulic properties measurement and the intra-unit heterogeneity estimated by the coupling of PTF and the unit-specific calibration function. This procedure is capable of transfer the "structural" information enclosed in the water retention curve (measured in each horizon of the representative soil profile) to the PTF applied in the same horizons of the soil mapping unit. 
iv. How the intra-unit and inter-unit variability can be reorganized according to hydrological reasons.

The case study 3 shows how pedological-driven soil mapping units were aggregated to form fewer hydrological-driven soil-landscape units (e.g. on the basis of the effective soil depth) for water balance purpose. This is an important contribute of pedology serving hydrology in cases a reduction of the discrepancies between the model (i.e. TOPKAPI) scale and the soil observation scale.

Another example worth mentioning concerning the soil map unit reorganization was presented in the case study 2 showing how it is likely to classify soils by defining some "functional properties", which describe the hydrological behaviour of the entire soil profile (Wösten et al., 1986; Bouma et al., 2008). This was performed coupling concepts reported in points (i), (ii) and (iii) in order to produce a map of Hydropedological Functional Unit. It is useful to emphasise that this approach shows large flexibility; in fact once the procedure has been applied very little adjunctive work is needed for addressing new hydrological tasks.

v. Finally we aim to emphasise the key issue concerning which soil horizons (features, properties) can be effective and then must be strongly acknowledged for hydrological purposes. For example, the application of PTF in soils with andic features can induce serious mistakes. We have provided some evidences throughout our case studies including (a) the presence/absence of fragipan horizon was a key factor in the aggregation of soil units into landscape units (case study 3); (b) soil profiles with the occurrence of thick mollic horizons - soil layers having high water storage capacity - enabled to aggregate otherwise different soil mapping units (case study 3 ).

In all given case studies, soil map database have been integrated with some extra soil hydrological data (fine tuning). The consequent high increase in cost for such an analysis can be fully justified only in a more inclusive hydropedological framework where the same information - in terms of forms and functions - can produce integrated results in different applications with a very similar data requirement.

In conclusion it is important to stress that an effective interaction between pedology and hydrology to address landscape and watershed hydrology can be very fruitful for both disciplines but yet there is much work to be done. More specifically we believe that the following must be considered key issues:

- greater awareness on the part of hydrologists about how much and what information, both directly and indirectly related to landscape hydrology, lies behind a soil map in the attached soil database;
- awareness on the part of pedologist of the need to move actual assessment of hydrological features/properties (i.e. runoff, cracking, permeability, flood, structure, mottles, etc.) from qualitative to quantitative or at least semi-quantitative schemes to better incorporate hydrological parameters in soil classification;

- the inclusion of quantitative information on soil spatial variability (e.g. variance, semivariogram) and spatial distribution of prediction errors within a new conception of soil maps. In this framework digital soil mapping can provide a major contribution to hydropedology;

- in a context of a wider environmental management planning, the use of a common base of mainly physical soil information can be a fundamental tool able to approach different soil hydrological processes.

\section{Appendix A}

\section{Soil mapping procedures}

\section{A1 Introduction}

Dokuchaev and Jenny, respectively in 1882 and 1941, first recognized and then attempted to formalize soil formation by the following equation: $s=f(\mathrm{cl}, o, r, p, t, \ldots)$ (worldwide known as CLORPT), where $s$ is any soil property, cl the climate, $o$ the organisms, $r$ the topography, $p$ the parent material (the state of the soil at time zero), $t$ the absolute age of the soil, and the dots ... represents additional non-specified factors or factors interaction.

In true landscapes, the above equation is both a powerful conceptual framework but it also shows limitation in producing a fine exhaustive spatial analysis of soils. This is because some of the factors of soil formation, formalized in the equation, are very difficult to be determined such as the age of pedogenesis and/or the status of other soil-forming CLORPT factors during the (long) life of a developing soil. Despite these difficulties, in the last century the scientific community of pedologists used the CLORPT conceptualization and standardized survey methods to analyse and report the spatial distribution of soils through the production of soil maps. These maps were then employed as indispensable tools for planning proper land management.

Some recent conceptualizations, reviews and local studies have been also performed on the use of mechanistic models of soil formation, partly based on the CLORPT conceptualization, at both point based and landscape based scales (Samouëlian and Cornu, 2008; Minasny et al., 2008; Salvador-Blanes et al., 2007).

More recently, soil scientists involved in spatial quantitative research have translated Jenny's mechanistic CLORPT 
formulation into the more quantitative and inference-based SCORPAN model (McBratney et al., 2003):

$S=f(s, c, o, r, p, a, n)$

where $S$ is the target soil property/class, $s$ stands for other soil information at the same location, $c$ is climate, $o$ is organisms, $r$ is topography, $p$ is parent material, $a$ is age, and $n$ stays for spatial position. Any factor can be formally expressed as a function of spatial $(x, y, z)$ and temporal $(t)$ coordinates, such that the target soil property can assume to the highest degree of complexity the form $S(x, y, z, t)$. However pedometricians very often employ the simpler bidimensional $S(x, y)$, while $S(x, y, z)$ is a bit used in the spatial three-dimensional modelling (e.g. Park and Vlek, 2002; Lark and Bishop, 2007), and the $S(x, y, t)$ template is sometimes used in spatio-temporal geostatistics (e.g. Bilonick, 1988; De Cesare et al., 2001a,b; Snepvangers et al., 2003). Here if not explicitly mentioned we refer to a simple bidimensional domain.

The SCORPAN formalization consists of an empirical quantitative description of relationships between soils and environmental factors with a view to using these as soil spatial prediction functions for determining the spatial distribution of soil types and soil attributes. It is an adaptation of CLORPT, not for a mechanistic explanation of soil formation but for an empirical representation of relationships between soil and other georeferenced factors. In SCORPAN this is obtained by extending the five soil forming factors with the addition of the spatial position $n$.

Digital Soil Mapping (DSM) is the production of maps of soil types and soil properties in digital format assisted by a computer. A detailed discussion of both conventional and DSM methods may be found in some reference books (Dent and Young, 1981; McKenzie et al., 2008).

It should be pointed out that conventional and digital soil mapping are integrated fields and an overall presentation should be given. However we prefer here a separate and brief description of these two complex procedures for the purpose of promoting an easy reading and understanding to the environmental hydrologists.

\section{A2 Conventional soil mapping}

The conventional approach describes the spatial complexity of soils in the landscape by means of an expert knowledge (mental) model developed by the pedologist using an implicit predictive model. It is strongly qualitative, complex and rarely communicated in a clear manner (it has an adaptation to each landscape). Basically the pedologists perform a preliminary spatial study of climate, land use, topography, geology and then investigate the spatial relationships between these environmental features and soils observed in the field and then analysed in the lab.

The approach has a high degree of subjectivity and uncertainty, and the soil spatial variability is generally not described. The main steps typically employed in producing soil maps are illustrated in Fig. A1 and include:

1. Acquisition of all available information on the spatial distribution of soil-forming factors (e.g. geological map, geomorphology, DEM, climate data, etc.) including those obtained after remote and proximal sensing.

2. A synopsis of all such information for producing a preliminary landscape classification. This synopsis, assisted by the use of photointerpretation (either analog or digital), consists in segmenting a region into many landscape units supposed, in this preliminary step, internally homogeneous in terms of soil-forming factors (at least those available). In other words, the procedure employs the strongly deterministic basis of the soil-forming factors to segment, with a first approximation, the region of interest into areas for carrying out soil sampling and analysis.

3. In these segmented areas a preliminary soil survey is then carried out. This survey consists in opening up holes and trenches (and also in performing hand drilling) where, following standardized procedures, a vertical section of soil called the soil profile and the site (about $10 \mathrm{~m}^{2}$ ) where the profile is located, are described.

4. The description typically consist in recognising different horizontal layers, called pedogenic horizons, and also in determining, for each of the identified horizons, specific features and properties that can be directly derived in the field (Soil Survey Staff, 1993; FAO, 2006). Finally, soils are sampled for chemical and physical analysis to be performed in the laboratory. An example of the kind of soil features that are described in a soil survey is given in Table 2 where we have highlighted in bold and italics those features which are of great relevance to hydrology.

5. Assuming a profile consisting of only three horizons, the potential output will include about 257 field data (including descriptions of the profile and the soil sampling station and in the theoretical case where that all types of soil features occur) and 36 laboratory-based data for each soil observation. Using the (qualitative, semi-quantitative, quantitative) field and laboratory data obtained, soils are then classified into categories using international systems of soil classification such as Soil Taxonomy (USDA, 2010) or World Reference Base (WRB, 2006).

6. On the basis of the results obtained after the preliminary soil survey, a preliminary soil mapping units (SMU) map is produced after a synopsis of both landscape and soil information (also named preliminary soil correlation). In this map, one or more soil types (Soil Typological Units also typically named as STU) are associated to each preliminary SMU. 


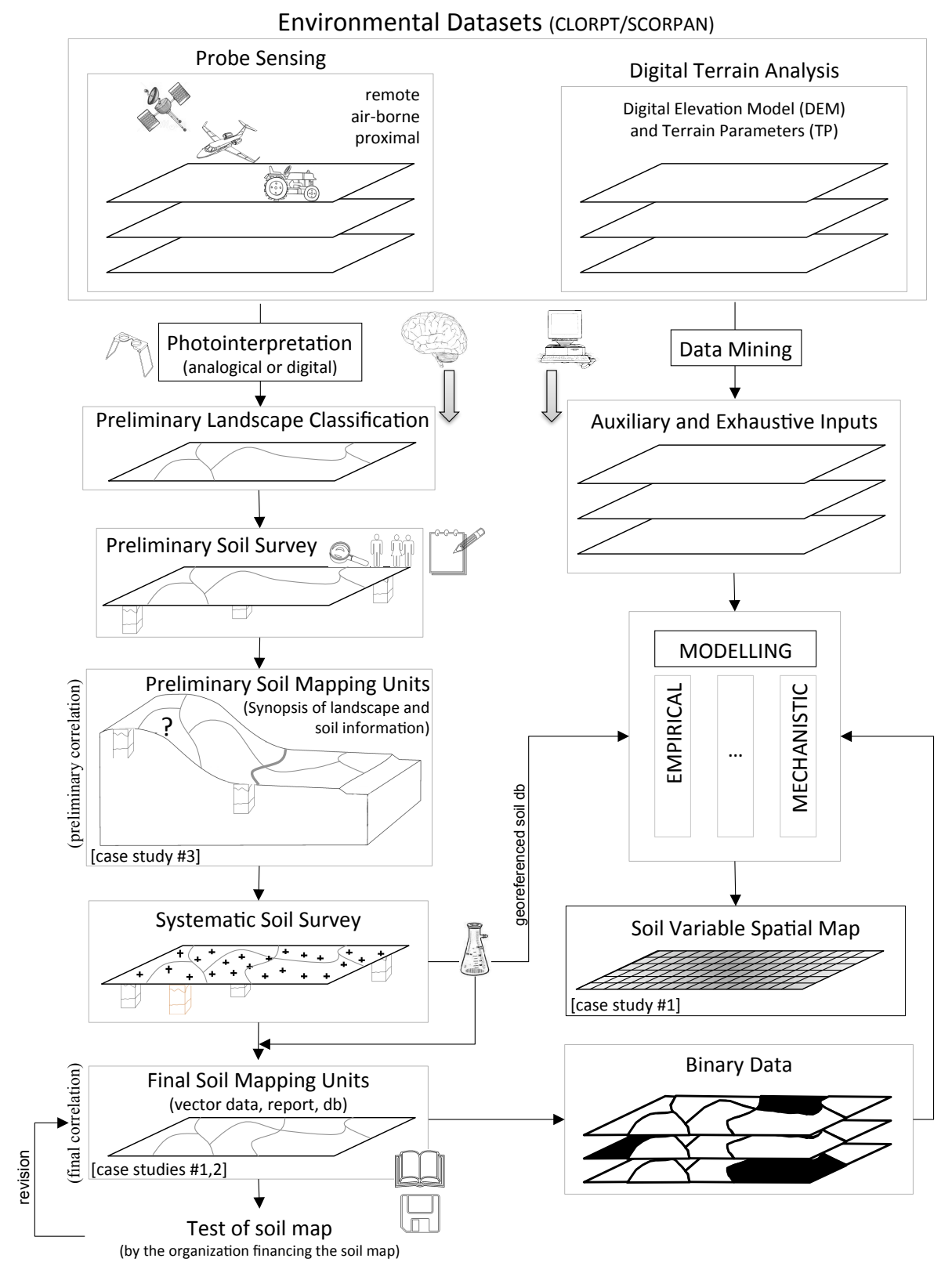

Fig. A1. Data flow of the main steps involved in both conventional (left panel) and digital (right panel) soil mapping. Some remarks: (i) the same set of environmental data can be used for conventional or digital soil mapping; (ii) to promote understanding the two mapping procedures are separately depicted with few key interaction points (e.g. lab data are used to calibrate SCORPAN like models and to co-define SMU).

7. Systematic soil survey (in accordance with standards required by the organization commissioning the survey) and soil analysis on the basis of the preliminary SMU map.

8. First draft of the final SMU map and soil legend (USDA, 1993). In this drafting process, the aim is to organize and produce a synthesis of all the soil knowledge in the study area within a coherent framework (typically named as final soil correlation). This rather complex task is typically performed by aggregating all soil information into a limited number of soil mapping units (SMU), each being represented by the dominant (and co-dominant) soil type (STU).

9. Field control to check soil mapping units and drafting of the final soil map (SMU) with explanatory notes where for each STU is also given a representative profile including field description and lab analysis. 
Table A1. Example of standards employed in soil survey and conventional soil mapping.

\begin{tabular}{|c|c|c|c|c|c|c|}
\hline Typical user & $\begin{array}{l}\text { Type of } \\
\text { scale }\end{array}$ & $\begin{array}{l}\text { Mapping } \\
\text { scale }\end{array}$ & $\begin{array}{l}\text { N. obs } \\
\text { (in } 100 \text { ha) }\end{array}$ & $\begin{array}{l}\text { Remotely } \\
\text { sensed } \\
\text { images }\end{array}$ & $\begin{array}{l}\text { Minimum } \\
\text { polygon } \\
\text { (ha) }\end{array}$ & $\begin{array}{l}\text { Cost } \\
\text { Euro ha }^{-1}\end{array}$ \\
\hline Country & Schematic & 1:1000000 & & $1: 100000$ & 4000 & n.a. \\
\hline $\begin{array}{l}\text { Country } \\
\text { Inter-region } \\
\text { Region }\end{array}$ & Inventory & $1: 250000$ & 0.16 & $1: 100000$ & 250 & $0.2-0.7$ \\
\hline $\begin{array}{l}\text { Province } \\
\text { District } \\
\text { Watershed authorities } \\
\text { Mountain communities }\end{array}$ & $\begin{array}{l}\text { Semi- } \\
\text { detailed }\end{array}$ & $1: 50000$ & $1-3$ & $\begin{array}{l}1: 20000 \\
1: 33000\end{array}$ & 15 & $7-10$ \\
\hline Municipal district & Detailed & $1: 25000$ & $10 / 50$ & 1:8000 & 2 & n.a. \\
\hline $\begin{array}{l}\text { Municipal district } \\
\text { Farms }\end{array}$ & Very detailed & $1: 5000$ & 100 & & 0.1 & $400-500$ \\
\hline
\end{tabular}

10. Final test of the soil map, typically performed by the organization commissioning the soil map.

11. Final review and publication and release (upon request) of .shp file and soil database.

What is evident here is the complexity of the process of surveying and mapping of soils, the large quantity of data to be processed and the importance of a good synopsis of the obtained soil knowledge.

Here we must emphasise that the information content of a conventional soil map, is obviously highly dependent on the scale. For the sake of this specific paper, we only report some examples of methods and standards in Table A1. From this table it is possible to emphasise that soil maps are typically made at very different scales and that moving from more general scales towards more detailed scales a sharp increase in the number of soil observations and their associated costs is observed.

\section{A3 Digital soil mapping}

Digital soil mapping can rely upon, but is distinct from, soil mapping (Fig. A1). Digitized and georeferenced soil survey information does not become DSM until they are used to derive other soil related information within a software application. New spatial soil information is generated by coupling (field and laboratory) observations at survey locations with exhaustive auxiliary information using inference systems. A soil inference system is a pedometric (mathematical or statistical) SCORPAN-like model and it can be spatial or non spatial according to the domain of inference, that is the inference takes place in the spatial or in the attribute domain, respectively. Inference systems use auxiliary information (SCORPAN factors) correlated to the target soil property/class (McKenzie and Ryan, 1999) and coming from different fields such as remote sensing (hyperspectral and multitemporal imagery at relative high spatial resolution), proximal sensing (e.g. electromagnetic induction scanning techniques), and digital terrain analysis (i.e. the calculation of derived terrain parameters using a Digital Elevation Model; Wilson and Gallant, 2000). This auxiliary information is also said to be exhaustive because it is densely available on a regular grid base to such an extent that every surveyed location and any unknown point are both covered. The prediction of a soil property at a given site is thus obtained from known observations about that property neighbouring the site and from exhaustive auxiliary data at both the known soil observations and the unknown site to be estimated under different neighbourhood schemes according to the type of the inference system used. In other words, a soil inference system is a way to select amongst several auxiliaries information and use the remaining predictive information to calibrate, validate and simulate the model at hand.

Much DSM work worldwide is based on the use of already existing soil databases (as laboratory-measured data using surveyed soil samples), and conventional and analogical soil cartography itself is not necessarily required. DSM thus typically consists in creating soil information combining point-based data (from field survey and laboratory analysis) and mostly exhaustive auxiliary information obtained at cheaper costs with models of inference in the spatial, temporal and/or attribute domains. According to the domain of inference, Carré et al. (2007) distinguished the DSM sensu stricto (DSMss) which is involved in the creation of soil information in the space domain, from the DSM sensu lato (DSMsl) which can generate derived soil attributes from the outputs of DSMss by mean of attribute domain inference systems (e.g. soil water retention capacity).

Products are commonly assessed for accuracy and uncertainty (Oliver, 2010). Accuracy is a key aspect of DSM 
procedures, also considering the linked structure of some inference systems (think to the cascade modelling using the DSMss and the DSMsl in sequence). The global accuracy of a DSM product depends upon the accuracy of the whole set of soil data (localization, sampling, measurements, etc.), the auxiliary covariates and the inference systems used. As an example of a DSM procedure a regression kriging model (Odeh et al., 1995) is here described in more detail (see Fig. 2.2 in Dobos et al., 2006):

1. There are soil profile observations that constitute the soil database of the area of interest (observation points).

2. Primary soil attributes are measured at these locations and the major inquiry is the knowledge of primary soil attributes at locations where no observations are available (unknown points).

3. The SCORPAN framework suggests that any soil property (target variable) is quantitatively related to other soil properties (point covariates) and to exhaustive auxiliary information (gridded covariates) pertaining to soil forming factors.

4. Considering the sources of gridded covariates (e.g. probe sensing and digital terrain analysis) and hence the amount of forthcoming variables, the first step consists in reducing the dimensionality of the input space by a factor analysis (or a principal component analysis). The resulting unobserved factors (or components) are queried at observation points to build the matching table (gridded to point covariates are added to pre-existent point covariates), which is used for calibrating the regression kriging model.

5. Regression kriging can be thought of as a two component model plus an error term.

a. At first stage the deterministic component is solved by a classical multilinear regression model (i.e. a fixed effects model with a single error term; Schabenberger and Pierce, 2002).

b. The stochastic component is engaged at second stage, in which the target variable residuals from regression are analysed for spatial auto and cross correlation by means of the main explorative tool in geostatistics, the semivariogram. The so called model of (co)regionalization is fulfilled by fitting allowed mathematical functions to experimental semivariograms, and then the (co)kriging system is mostly solvable.

c. Regression and geostatistical predictions at unknown gridded points are additively combined in order to obtain the regression kriging predictions (gridded predictions).
6. A regression kriging map of the target soil attribute is fulfilled. It can be considered an output itself or can be used in cascade modelling as an input in order to address functional properties of soils.

\section{Appendix B}

\section{Glossary of soil terms (relevant for this specific paper)}

The following terms are given to elucidate definitions for those unfamiliar with the soil survey and soil mapping fields. The soil survey glossary refers to terms given in FAO (2006) and in Soil Science Society of America (2003). The soil mapping definitions are partly extracted from the report of the Digital Soil Mapping Working Group (Dobos et al., 2006). Terms are in alphabetical order.

\section{B1 Soil survey (field description): basic concepts and definitions}

\section{- Andic features:}

(from Japanese An, dark, and Do, soil) it refers to horizons resulting from moderate weathering of mainly pyroclastic deposits and dominated either by short-rangeorder clay minerals and/or and $\mathrm{Al} / \mathrm{Fe}$-humus complexes.

Andic features may be found both at the surface and in the subsurface. Surface andic horizon generally contain a high amount of organic matter (more than $5 \%$ ), are very dark coloured have a fluffy macrostructure. Both surface and subsurface horizons exhibit smeary consistence, thixotropy, low bulk density, very high water retention and have silt loam or finer textures.

Since analytical difficulties implied in identifying the occurrence of short-range-order clay minerals and $\mathrm{Al} / \mathrm{Fe}$-humus complexes the following chemical/physical test are considered diagnostic: (i) bulk density of the soil at field capacity (no prior drying) of less than $0.9 \mathrm{~kg} \mathrm{dm}^{-3}$; (ii) acid oxalate extractable aluminium and iron (named Alox $+1 / 2$ Feox) must be either larger than $2.0 \%$ or between $0.4-2.0 \%$ but in this case the occurrence other soil features (e.g. estimate of volcanic glass) are required; (iii) phosphate retention of $70 \%$ or more; (iv) volcanic glass content in the fine earth fraction and (v) thickness of at least $30 \mathrm{~cm}$.

\section{- Biological features:}

Biological features, such as krotovinas, termite burrows, insect nests, worm casts and burrows of larger animals, are described in terms of abundance and kind. In addition, specific locations, patterns, size, composition or any other characteristic may be recorded. 
- Carbonates:

the presence of calcium carbonate $\left(\mathrm{CaCO}_{3}\right)$ is established by adding some drops of $10 \% \mathrm{HCl}$ to the soil. The degree of effervescence of carbon dioxide gas is indicative for the amount of calcium carbonate presence.

\section{- Coating:}

Layer of a substance completely or partly covering a surface of soil material; coatings can comprise clay, calcite, gypsum, iron, organic material, salt, etc. These features are described according to their abundance, contrast, nature, form and location.

\section{- Concentrations:}

are identifiable bodies within the soil that were formed by pedogenesis, including secondary enrichments, cementations and reorientations (FAO, 2006). Some of these bodies are thin and sheet like; some are nearly equidimensional; others have irregular shapes. They may contrast sharply with the surrounding material in strength, composition, or internal organization. Alternatively, the differences from the surrounding material may be slight.

\section{- Concretion:}

A cemented concentration of a chemical compound, such as calcium carbonate or iron oxide, that can be removed from the soil intact and that has crude internal symmetry organized around a point, line, or plane.

\section{- Drainage Classes (natural):}

Natural drainage class refers to the frequency and duration of wet periods under conditions similar to those under which the soil developed. Alteration of the water regime by man, either through drainage or irrigation, is not a consideration unless the alterations have significantly changed the morphology of the soil. The classes follow:

\section{a. Excessively drained}

Water is removed from the soil very rapidly. The occurrence of internal free water commonly is very rare or very deep. The soils are commonly coarse-textured and have very high saturated hydraulic conductivity or are very shallow.

\section{b. Somewhat excessively drained}

Water is removed from the soil rapidly. Internal free water occurrence commonly is very rare or very deep. The soils are commonly coarse-textured and have high saturated hydraulic conductivity or are very shallow.

\section{c. Well drained}

Water is removed from the soil readily but not rapidly. Internal free water occurrence commonly is deep or very deep; annual duration is not specified. Water is available to plants throughout most of the growing season in humid regions. Wetness does not inhibit growth of roots for significant periods during most growing seasons. The soils are mainly free of the deep to redoximorphic features that are related to wetness.

\section{d. Moderately well drained}

Water is removed from the soil somewhat slowly during some periods of the year. Internal free water occurrence commonly is moderately deep and transitory through permanent. The soils are wet for only a short time within the rooting depth during the growing season, but long enough that most mesophytic crops are affected. They commonly have a moderately low or lower saturated hydraulic conductivity in a layer within the upper $1 \mathrm{~m}$, periodically receive high rainfall, or both.

\section{e. Somewhat poorly drained}

Water is removed slowly so that the soil is wet at a shallow depth for significant periods during the growing season. The occurrence of internal free water commonly is shallow to moderately deep and transitory to permanent. Wetness markedly restricts the growth of mesophytic crops, unless artificial drainage is provided. The soils commonly have one or more of the following characteristics: low or very low saturated hydraulic conductivity, a high water table, additional water from seepage, or nearly continuous rainfall.

\section{f. Poorly drained}

Water is removed so slowly that the soil is wet at shallow depths periodically during the growing season or remains wet for long periods. The occurrence of internal free water is shallow or very shallow and common or persistent. Free water is commonly at or near the surface long enough during the growing season so that most mesophytic crops cannot be grown, unless the soil is artificially drained. The soil, however, is not continuously wet directly below ploughing depth. Free water at shallow depth is usually present. This water table is commonly the result of low or very low saturated hydraulic conductivity of nearly continuous rainfall, or of a combination of these.

\section{g. Very poorly drained}

Water is removed from the soil so slowly that free water remains at or very near the ground surface during much of the growing season. The occurrence of internal free water is very shallow and persistent or permanent. Unless the soil is artificially drained, most mesophytic crops cannot be grown. The soils are commonly level or depressed and frequently ponded. If rainfall is high or nearly continuous, slope gradients may be greater.

\section{- Horizon:}

see soil horizon. 
- Horizon Boundary:

Horizon boundaries are described in terms of depth, distinctness and topography. The depth of the upper and lower boundaries of each horizon is given in centimetres, measured from the surface (including organic and mineral covers) of the soil downwards.

- Inundation occurrence:

A record of the month(s) during which the inundation occurs may be useful. Maximum depth of the inundation, as well as the flow velocity, may be helpful.

- Minipit:

a quick (and low cost) small soil excavation aiming either/both to check the occurrence and sample specific soil horizons.

- Mottling:

Mottles are spots or blotches of different colours or shades of colour interspersed with the dominant colour of the soil. They indicate that the soil has been subject to alternate wetting (reducing) and dry (oxidizing) conditions. Mottling of the soil matrix or groundmass is described in terms of abundance, size, contrast, boundary and colour. In addition, the shape, position or any other feature may be recorded.

- Porosity:

The total volume of voids in a soil sample (nonsolid volume) discernible with $a \times 10$ hand-lens measured by area and recorded as the percentage of the surface occupied by pores. Voids are described in terms of type, size, abundance, continuity and orientation.

- Reaction, soil:

The degree of acidity or alkalinity of a soil, usually expressed as a $\mathrm{pH}$ value. Descriptive terms commonly associated with certain ranges in $\mathrm{pH}$.

- Rock fragments:

Unattached pieces of rock $2 \mathrm{~mm}$ in diameter or larger those are strongly cemented or more resistant to rupture. Rock fragments are described by size, shape, and, for some, the kind of rock. The classes are pebbles, cobbles, channers, flagstones, stones, and boulders.

- Slickensides:

Stress surfaces that are polished and striated produced by one mass sliding past another. Slickensides are common below $50 \mathrm{~cm}$ in swelling clays subject to large changes in water content.

- Soil colour (matrix):

soil colour is one of the indicators of soil status and depends on many factors. The colour of the soil matrix of each horizon should be recorded in the moist condition (or both dry and moist conditions where possible) using the notations for hue, value and chroma as given in the
Munsell Soil Color Charts (Munsell, 1975). For example: 10 YR $6 / 4$ is a colour (of soil) with a hue $=10 \mathrm{YR}$, value $=6$, and chroma $=4$.

\section{- Soil horizon:}

A layer of soil or soil material approximately parallel to the land surface and differing from adjacent genetically related layers in physical, chemical, and biological properties or characteristics such as colour, structure, texture, consistency, kinds and number of organisms present, degree of acidity or alkalinity, etc. Soil horizons include the following designation:

\section{- O horizons}

Layers dominated by organic material.

\section{- A horizons}

Mineral horizons that formed at the surface characterized by an accumulation of humified organic matter or have properties resulting from cultivation, pasturing, or similar kinds of disturbance.

\section{- E horizons}

Mineral horizons in which the main feature is loss of silicate clay, iron, aluminium, or some combination of these, leaving a concentration of sand and silt particles of quartz or other resistant materials.

\section{- B horizons}

Horizons that formed below an A, E, or O horizon and are dominated by obliteration of all or much of the original rock structure and show one or more of the following (a) illuvial concentration of silicate clay, iron, aluminium, humus, carbonates, gypsum, or silica, alone or in combination; (b) evidence of removal of carbonates; (c) residual concentration of sesquioxides; (d) coatings of sesquioxides; (e) alteration that forms silicate clay or liberates oxides or both and that forms granular, blocky, or prismatic structure;

- Chorizons

Layers, excluding hard bedrock, that are little affected by pedogenic processes and eventually.

- R layers

Hard bedrock.

- Soil profile:

Vertical section of soil horizons from upper layer to the parent material, showing the arrangement (configuration) of soil horizons typical for single soil types and used as a basis for soil classification.

\section{- Soil structure:}

The combination or arrangement of primary soil particles into secondary units or peds. The secondary units are characterized on the basis of size, shape (platy, prismatic, columnar, angular, subangular, blocky, granular, 
etc.), and grade (degree of distinctness: single-grain, massive, weak, moderate, and strong).

\section{- Soil texture}

(of the fine earth fraction): numerical proportion (\% by wt.) of sand, silt and clay in a soil (for particles less than $2 \mathrm{~mm}$ ). Sand, silt and clay content are estimated in the field, and/or quantitatively in the laboratory, and then placed within the texture triangle to determine soil texture class. Texture can be coarse (sand particles predominate), medium (silt particles predominate), or fine (clay particles predominate).

\section{B2 Soil mapping: basic concepts and definitions}

\section{- Collocated soil attributes:}

Any covariate available at the same observation points than the target soil attribute. Typically these are other soil attributes used to predict the target soil attribute.

\section{- Covariates.}

All the variables related to the target soil attribute and pertaining to the SCORPAN factors. These variable can be collocated soil attributes (e.g. other soil attributes) or can be exhaustive auxiliary information (e.g. derivatives of a digital elevation model or a geophysical spectrum).

\section{- Digital Soil Map:}

Visualization of a georeferenced soil database, which shows spatial distribution of soil types and/or soil properties; digital soil map can also be a digitized existing soil maps.

\section{- Digital Soil Mapping:}

It is the computer-assisted production of digital maps of soil type and soil properties. It typically implies use of mathematical and statistical models that combine information from soil observations with information contained in correlated environmental variables and remote sensing images.

- Exhaustive auxiliary information (or exhaustive ancillary data):

The set of covariates derived from probe scanning, digital terrain analysis or other digital/digitized maps. This set of data is exhaustive because of its gridded nature (generally the gridded points are not perfectly collocated with the target soil attribute recalling for a data migration procedure). The term auxiliary refers to the aid this set provides within any soil inference system in producing a digital soil map.

\section{- Functional maps:}

Visualisation of soil database (a complex document) usable in its current form to any further application, due to its complex description of how it was derived, what accuracy does it have (metadata), how to interpret, what it can be used for; maps easy to use for practical purposes; multifunctional maps.

- Secondary soil properties:

These are properties derived from primary soil properties using various inference models (pedotransfer rules and environmental models).

\section{- Soil classification:}

Soils are named and classified on the basis of physical and chemical properties in their horizons (layers). Soil classification schemes typically use colour, texture, structure, and other properties of the surface two meters deep to key the soil into a classification system to help people use soil information (modified after Soil Survey Manual).

\section{- Soil functions:}

Various ecologic and socio-economic roles of soils, as defined in the COM179 (2002) regulation; the most important soil functions are (a) soil biomass productivity, (b) organic carbon fixation, (c) groundwater protection, (d) support for raw material, (e) biodiversity, and (f) natural heritage.

- Soil mapping:

It is the process of mapping soil types or other properties over a landscape. It relies heavily on distinguishing the individual influences of the five classic soil forming factors. This effort draws upon geomorphology, physical geography, and analysis of vegetation and land-use patterns.

\section{Soil observations:}

Measured and observed data available from original soil survey.

\section{- Soil spatial inference:}

A procedure or a set of procedures implementing a soillandscape model also known as the "SCORPAN" model used to derive soil properties or classes using available soil and auxiliary information.

\section{- Soil survey:}

Describes the characteristics of the soils in a given area, classifies the soils according to a standard system of classification, plots the boundaries of the soils on a map, and makes predictions about the behaviour of soils. The different uses of the soils and how the response of management affects them are considered. The information collected in a soil survey helps in the development of land-use plans and evaluates and predicts the effects of land use on the environment (Soil survey manual).

- Spatially predicted soil properties/classes:

Interpolated soil properties or classes that are now available at each location in the area of interest. This is the output from the soil spatial inference system. 
- Target soil attribute:

Any soil property/class analysed within a soil spatial inference framework to make a digital soil map.

\section{Appendix C}

\section{Hydrological models}

\section{C1 ALMAGRA model - MicroLEIS DSS (De La Rosa et al., 2004)}

This model is part of a more general agro-ecological land evaluation Decision Support System (DSS), which is the MicroLEIS DSS. This DSS is based on the multifunctional evaluation of soil quality, using input data collected in standard soil surveys.

It aims to define site-specific sustainable agricultural practices and to point out the importance of using soil information in decision-making regarding the environmentally sustainable use and management of land.

Basically the ALMAGRA model uses a multiparametric approach to determine classes of land productivity for a specific crop. The land parameters correspond to the following three main factors: soil/site, climate and crop/management.

The employed soil parameters are selected as important soil indicators for specific soil functions such as the crop productivity. These parameters include functional depth, stoniness, texture, water retention, reaction, carbonates, salinity, and cation exchange capacity.

On the base of values of these parameters in the different soil mapping units (as given in the soil database), the MicroLEIS system classifies - according to the most limiting factor and through a matching table - suitability classes for the chosen crop. It also implements a specific module for maize crop.

The model can be freely downloaded at http://www. microleis.com.

\section{C2 Soil Water Atmosphere Plant (SWAP) model (van Dam et al., 1997)}

Applied version 2.07 of SWAP was designed for simulation of water flow, solute transport, and plant growth in the soilwater-atmosphere-plant continuum. To calculate soil water flow SWAP, using an implicit finite difference scheme, solves the 1-D Richards' equation for soil water movement in the soil matrix extended by the sink term, $S$ :

$$
\frac{\partial \theta(h)}{\partial t}=\frac{\partial}{\partial z}\left[K(h)\left(\frac{\partial h}{\partial z}+1\right)\right]-S(h)
$$

where $\theta\left(\mathrm{cm}^{3} \mathrm{~cm}^{-3}\right)$ is the volumetric soil water content, $h$ $(\mathrm{cm})$ is the soil water pressure head, $t(\mathrm{~d})$ is the time, $z(\mathrm{~cm})$ is the vertical coordinate taken positively upward, $K\left(\mathrm{~cm} \mathrm{~d}^{-1}\right)$ is the hydraulic conductivity, and $S\left(\mathrm{~cm}^{3} \mathrm{~cm}^{-3} \mathrm{~d}^{-1}\right)$ is the water extraction rate by the plant roots. SWAP applies the equation both for the unsaturated and the saturated zones. The hydraulic conductivity is calculated as the arithmetic mean of the conductivities in the adjacent nodes. This hydrological model permits the definition of up to five soil layers with different physical properties. Additionally, the soil is subdivided into a maximum of 40 compartments in which the soil water flow is calculated with a daily time step.

Soil water retention was described by the unimodal $\theta(h)$ relationship proposed by van Genuchten (1980) and expressed here in terms of the effective saturation, $S_{\mathrm{e}}$, as follows:

$S_{\mathrm{e}}=\left[\frac{1}{1+(\alpha|h|)^{n}}\right]^{m}$

with $S_{\mathrm{e}}=\left(\theta-\theta_{\mathrm{r}}\right) /\left(\theta_{0}-\theta_{\mathrm{r}}\right), \theta_{r}$, and $\theta_{0}$ being the residual water content at $h=-\infty$ and the water content at $h=0$, respectively, and in which $\alpha\left(\mathrm{cm}^{-1}\right), n$, and $m$ are curve-fitting parameters.

Mualem's expression was applied to calculate the relative hydraulic conductivity, $K_{\mathrm{r}}$ (Mualem, 1976). Assuming $m=1-1 / n$, van Genuchten (1980) obtained a closed form analytical solution to predict $K_{\mathrm{r}}$ at specified volumetric water content:

$K_{\mathrm{r}}\left(S_{\mathrm{e}}\right)=\frac{K\left(S_{\mathrm{e}}\right)}{K_{0}}=S_{\mathrm{e}}^{\tau}\left[1-\left(1-S_{\mathrm{e}}^{1 / m}\right)^{m}\right]^{2}$

in which $K_{0}$ is the hydraulic conductivity at $\theta_{0}$, and $\tau$ is a parameter which accounts for the dependence of the tortuosity and partial correlation between pores of the same diameter. The condition at the bottom boundary can be set in several ways (e.g. pressure head, water table depth, fluxes, impermeable layer, unit gradient, etc.).

SWAP simulated the water uptake and actual transpiration according to the model proposed by Feddes et al. (1978), where root water uptake $S$ is described as a function of the pressure head, $h$ :

$S(h)=\alpha(h) S_{\max }=\alpha(h) T_{\mathrm{p}} / z_{\mathrm{r}}$

being $S_{\max }\left(\mathrm{d}^{-1}\right)$ the maximal possible root water uptake under optimal soil water condition, $T_{\mathrm{p}}\left(\mathrm{cm} \mathrm{d}^{-1}\right)$ is the potential transpiration rate, $z_{\mathrm{r}}(\mathrm{cm})$ the thickness of the root zone, and $\alpha(h)$ an empirical function of pressure head $h$, varying between 0 and 1. The shape of the function $\alpha(h)$ depends on four critical values of $h$, which are related to crop/vegetation type and to potential transpiration rates. Integration of $S$ over the root layer yields the actual transpiration rate $T_{\mathrm{a}}\left(\mathrm{cm} \mathrm{d}^{-1}\right)$. If the simpler crop model routine is chosen, the root depth, the leaf area index $(\mathrm{LAI})$, and the crop coefficient $\left(K_{\mathrm{C}}\right)$ are specified by the user as a function of the crop/plant development stage.

\section{C3 CropSyst (Stöckle et al., 2003)}

CropSyst is a multi-year multi-crop daily time step simulation model. The model has been developed to serve as an 
analytic tool to study the effect of cropping systems management on productivity and the environment. The model simulates the soil water budget, soil-plant nitrogen budget, crop canopy and root growth, dry matter production, yield, residue production and decomposition, and erosion. Analogy to Swap model, also CropSyst calculates the soil water flow solving the Richards' equation for soil water flow in the soil matrix by an implicit finite difference scheme.

In CropSyst the soil hydraulic functions are described by the analytical expressions of Campbell (1985). The soil water retention function is

$h=h_{b} \quad$ for $\quad h \geq h_{b}$

$h=h_{b}\left(\theta / \theta_{0}\right)^{-\lambda} \quad$ for $\quad h<h_{b}$

where $h_{b}$ is the air entry water potential (potential at which the largest water filled pores just drain), and $\lambda$ is the slope of $\ln (h)$ vs. $\ln (\theta)$. The hydraulic conductivity is described by

$K(h)=K_{0}\left(h_{b} / h\right)^{(2+3 / \lambda)}$.

The condition at the bottom boundary can be set in several ways (e.g. pressure head, water table depth, fluxes, impermeable layer, unit gradient, etc.). The number of soil layers (horizons) can be selected by the user until to 11 ; then CropSyst subdivides the layers automatically into sublayers of approximately $10 \mathrm{~cm}$ thickness.

In CropSyst model each layer water uptake is calculated as a function of (i) the difference between soil and xylem water potential and (ii) root conductance (Stöckle et al., 1992). The soil conductance is assumed to be higher than root conductance so water movement towards the roots does not limit that water uptake. The water uptake, $\mathrm{WU}_{i}\left(\mathrm{~kg} \mathrm{~m}^{-2} \mathrm{~d}^{-1}\right)$, from each soil layer $i$ is given by:

$\mathrm{WU}_{i}=86400 C_{i} / 1.5\left(\psi_{\mathrm{s} i}-\psi_{1}\right)$

where $\psi_{\mathrm{s} i}\left(\mathrm{~J} \mathrm{~kg}^{-1}\right)$ is the soil water potential of soil layer $i$ (Campbell, 1985), $\psi_{1}\left(\mathrm{~J} \mathrm{~kg}^{-1}\right)$ is the leaf water potential, $C_{i}$ $\left(\mathrm{kg} \mathrm{s} \mathrm{m}^{-4}\right)$ is the roots conductance of soil layer $i, 86400$ is the number of seconds per day and 1.5 is a factor that converts total root conductance to total plant hydraulic conductance. The total water uptake WU is the sum of the water uptake from each soil layer.

The crop growth is simulated for the whole canopy by calculating unstressed biomass growth as the minimum of two values of daily aboveground biomass rate. In fact, such rate is calculated as function of potential transpiration and of intercepted radiation. Unstressed biomass growth value is then corrected by water and nitrogen limitations to simulate actual daily biomass accumulation. The root growth is synchronized with leaf area growth (Stöckle et al., 2003). The water stress reduces biomass accumulation (and consequently LAI and roots development) proportionally to the actual to potential evapotranspiration ratio. The user gives the maximum value of root depth as input and the root density is assumed to decrease linearly with depth (Campbell and Diaz, 1988) with a maximum at the top of the soil profile and a value of zero at the tip of the current root depth.

\section{C4 USBR model for irrigability classes (http://www.fao.org/docrep)}

Sophisticated methods of land classification for irrigated agriculture were first evolved by the United States Bureau of Reclamation in the 1920s and 1930s.

The USBR classification system incorporates broad economic considerations from the start. This is important because irrigation projects generally involve costly inputs and improvements such as engineering works, irrigation and drainage networks, land clearing and levelling, and others.

The USBR Reclamation Manual (1951) and subsequent Reclamation Instructions lists the following principles of the USBR classification system:

1. Prediction: the classification should reflect future conditions as they will exist after the project is implemented. This recognizes that changes will occur in relationships between soils, water and crops as a result of irrigation and land improvements and that the classifier should use the classes to indicate whether these changes are likely to be favourable or unfavourable.

2. Economic correlation: this assumes that a unique relationship can be established during a classification, between physical conditions of the land such as soils, topography and drainage and an economic measure of the class ranges. The measure used is payment capacity, i.e. the residual available to defray the cost of water after all other costs have been met by the farmers.

3. Permanent and changeable factors: the classifier must distinguish between permanent factors, such as soil texture, soil depth, macro relief, etc., and changeable factors, such as salinity, ESP, pH, micro relief, nutrient status, water table levels, etc. Thus the survey and classification are directed to determining which inputs and improvements to changeable factors are cost effective.

4. Arability-irrigability: land which is physically and economically capable of providing a farmer with an adequate standard of living, should water be available for irrigation is first classified. Such land is called "arable" (connoting a different meaning of the word to that in common usage). Arable lands constitute areas that warrant consideration for inclusion in a plan of development. Lands which are selected for inclusion in the plan of development are called "irrigable" lands. This dual stage procedure is copied in this publication in the successive classification of "provisionally-irrigable" and "irrigable" land. 
The selection of lands for irrigation is phased into two parts:

- the selection of arable land on the basis of farm production financial considerations;

- selection of the irrigable area on the basis of the economics of the project plan, wherein irrigation benefits determined by economic evaluation equal or exceed project irrigation costs.

Six land classes based on production economics are normally recognized. Brief descriptions are as follows:

1. Arable: lands that are highly suitable for irrigated farming, being capable of sustained and relatively high yield of climatically adapted crops at reasonable cost. These lands have a relatively high payment capacity.

2. Arable: lands that have a moderate suitability for irrigated farming. These are either adaptable to a narrower range of crops, more expensive to develop for irrigation, or less productive than Class 1. Potentially these lands have intermediate payment capacity.

3. Arable: lands that have a marginal suitability for irrigated farming. They are less suitable than Class 2 lands and usually have either a serious single deficiency or a combination of several moderate deficiencies in soil, topography, or drainage properties. Although greater risk may be involved in farming these lands than those of Class 1 and 2, under proper management they are expected to have adequate payment capacity.

4. Special use lands: lands that in the USA are only suited to certain special uses (e.g. rice, pasture, or fruit) are classified 1, 2 or 3 (to reflect relative payment capacity) along with the appropriate letter designating the land use (crop).

5. Non-arable: this land is temporarily considered as nonarable because of some specific deficiency such as excessive salinity, questionable drainage, flooding, or other deficiency which requires further studies to resolve. The deficiency or deficiencies are of such a nature and magnitude that special agronomic, economic, or engineering studies are required to resolve the costs or effect on the land. Class 5 designation is tentative and should be changed to either Class 6 or an arable classification during formulation of the recommended plan of development.

6. Non-arable: land that is non-arable under the existing or project economic conditions associated with the proposed project development. Generally, Class 6 comprises steep, rough, broken, rocky, or badly eroded lands, or lands with inadequate drainage, or other deficiencies. In some instances lands considered to be
Class 6 in one area may be arable in another area because of different economic conditions. In addition to various physical-type deficiencies that result in a nonarable classification, lands initially classified as arable (potentially irrigable) on the basis of payment capacity (farm financial analysis) may be found non-arable if subsequent economic analysis (benefit analysis) indicates that benefits from such lands are less than their costs in a plan of development. Thus, the lower arable class(es) of lands would be considered non-arable and, of course, non-irrigable for economic reasons.

Lower case letters that indicates the reason for the land being downgraded to a lower class indicates subclasses. Thus, Class 1 land does not have subclasses, but other classes may be appended with the letters " $s$ ", " $t$ ", and " $d$ ", singly or in combination to show whether the deficiency is in "soils", "topography" or "farm drainage". The basic subclasses of the land classes are $s, t, d$, st, sd, td and std.

The model developed by Arangino et al. (1986) is a modification of this well known USBR model for adapting it at the Italian situation. It was adopted in many Italian irrigation projects of last 3 decades funded by Cassa per il Mezzogiorno.

The model classifies 4 irrigation suitability classes on the base of a multiparametric scheme including soil, topography and drainage features.

Soil features include texture, depth, stoniness, rockiness, permeability, mineral weathering, salinity and carbonates. Topographic features include slope angle and potential risk of erosion.

On the base of values of these parameters in the different soil mapping units an irrigation suitability map is produced.

\section{C5 TOPKAPI (Liu et al., 2005)}

TOPKAPI is a physically based, fully distributed rainfallrunoff model, which is based on the lumping of a kinematic wave assumption in the soil, at the surface, and in the drainage network and leads to transforming the rainfallrunoff and runoff routing processes into three nonlinear reservoir differential equations. Initially, the TOPKAPI model (Ciarapica and Todini, 2002; Liu and Todini, 2002) was structured around five modules that represent the evapotranspiration, snowmelt, soil water, surface water, and channel water. In a more recent work (Liu et al., 2005), the ground water component also has been developed. Many applications of the model have been implemented, especially for flood forecasting purposes (Martina and Entekhabi, 2006; Todini, 2007; Vischel et al., 2008).

The TOPKAPI model is based on the idea of combining the kinematic approach with the topography of the basin; the latter is described by a digital elevation model (DEM) that subdivides the application domain by means of a grid of square cells whose size generally increases with the overall 
dimensions because of the constraints imposed by the computing resources. Consequently, increasing the application scale of the model implies an increase in the dimensions of the cells, which at catchment scale may amount to several hundred metres per side. Each cell of the DEM is assigned a value for each of the physical characteristics represented in the model. The flow paths and slopes are evaluated, starting from the DEM, according to a neighbourhood relationship based on the principle of the minimum energy cost, namely the maximum elevation difference. It considers the links between the active cell and the four surrounding cells connected along the edges from the finite difference approach underpinning the model; the active cell is assumed to be connected downstream with a sole cell, while it can receive upstream contributions from more than one cell (up to three). The integration in space of the nonlinear kinematic wave equations results in three "structurally similar", zero-dimensional, nonlinear reservoir equations. The first represents the drainage in the soil, the second represents the overland flow on saturated or impervious soils, and the third represents the channel flow.

The TOPKAPI model proposed is structured around three basic modules that represent, in turn, the soil water component, the surface water component, and the channel water component (drainage network component). The deep aquifer flow gives no significant response to storm events. The soil water component is affected by a flow of water (interflow or subsurface flow) in a horizontal direction in conditions of no saturation, defined as drainage; drainage occurs in a surface soil layer, of limited thickness, and with high hydraulic conductivity because of its macroporosity. The drainage mechanism plays a fundamental role in the model both as a direct contribution to the flow in the drainage network and, most of all, as a factor regulating the soil water balance, particularly with regard to activating the production of overland flow (Todini, 1996). The soil water component is the most characterising aspect of the model because it regulates the functioning of the contributing saturated areas. The surface water component is activated on the basis of this mechanism. Lastly, both components contribute to feed the drainage network.

The other important aspect which is strongly related to the integration of the governing equations is the consequent unavoidable parameters (and variables) averaging. The question is whether the average parameters at the model scale are sufficient to model the dominant physical processes or the inner parameters space-distribution is necessary for a correct representation. That would imply, for instance, a model grid refinement up to the scale at which the space-distribution can be neglected.

In the context of rainfall-runoff modelling, we are mainly interested to the water flow both into the soil and over the surface; it is worth then to test the influence of the parameters averaging on these processes. It is convenient also to distinguish the vertical from the horizontal average.
Soil hydraulic behaviour is characterized by the soil water retention curve, which defines the water content $(\tilde{\theta})$ as a function of the capillary pressure head $(\psi)$, and the hydraulic conductivity function, which establishes relationship between the hydraulic conductivity $(K)$ and water content or capillary pressure head. Simulations of unsaturated flow and solute transport typically use closed-form functions to represent water-retention characteristics and unsaturated hydraulic conductivities. Some of the commonly used functional relationships include the Brooks-Corey model, and the van Genuchten model. Both models can be used to compute the hydraulic transmissivity $(T)$ of a soil layer in non-saturated condition which is given by the following expression:

$T=\int_{0}^{L} k(\theta(z)) \cdot \mathrm{d} z$

where $z$ is the vertical direction and $L$ is the thickness of the layer affected by the horizontal flow. The water flow can be calculated, assuming a kinematic wave approximation, from the actual soil moisture profile as:

$q=\int_{0}^{L} \tan (\beta) k(\tilde{\vartheta}(z)) \mathrm{d} z$

where $\beta$ is the topographic surface slope assumed to be equal to the water table slope and $q$ is the water flow per unit soil width $\left[\mathrm{m}^{2} \mathrm{~s}^{-1}\right]$.

As it can be seen from Eq. (C9) the horizontal water flow depends on the particular soil moisture profile since there is not a linear relationship between unsaturated conductivity and volumetric water volume. However, due to the high conductivity value, caused by macropores in the top of the soil, gravity will be the dominant mechanism driving water from the top of the soil to the bottom (impermeable or semi-impermeable lower boundary). In this zone within the range of reasonable errors, the integration of the unsaturated soil vertical infiltration equation (namely Richards' equation) and use only the average values for hydraulic conductivity and water content to compute the transmissivity (and consequently the water flow). As a matter of fact in the TOPKAPI model the transmissivity is given by:

$T=L \cdot k_{\mathrm{s}} \tilde{\Theta}^{\alpha}$

where $k_{\mathrm{S}}$ is the saturated hydraulic conductivity, $\alpha$ is a parameter dependent on the soil characteristics and $\tilde{\Theta}$ is mean water content along the vertical profile i.e.:

$\tilde{\Theta}=\frac{1}{L} \int_{0}^{L} \tilde{\theta}(z) \mathrm{d} z$.

The feasibility of this assumption has been validated by a numeric experiment where the transmissivity computed considering the vertical profile of the water content (Eq. C8) is 
Table C1. Principal parameters required for each grid cell in the new TOPKAPI model.

\begin{tabular}{|c|c|}
\hline Model Component & Parameter \\
\hline Interception & $\begin{array}{l}\text { Vegetation interception capacity }\left(S_{\mathrm{r} 0}\right) \\
\text { Vegetation storage capacity }\left(\mathrm{SC}_{0}\right) \\
\text { Maximum leaf-area-index }\left(\mathrm{LAI}_{0}\right)\end{array}$ \\
\hline Evapotranspiration & $\begin{array}{l}\text { Daily maximum sunshine hours }(n) \\
\text { Monthly average air temperature }\left(T_{\mathrm{a}}\right) \\
\text { Crop factors }\left(K_{\mathrm{c}}\right)\end{array}$ \\
\hline Snowmelt & Critical air temperature for determining the precipitation as snow or rain, $T_{\mathrm{S}}$ \\
\hline Infiltration & Infiltration coefficient depending on the land cover type $\left(K_{1}\right)$ \\
\hline Interflow and percolation & $\begin{array}{l}\text { Thickness of the upper soil layer }(L) \\
\text { Horizontal and vertical saturated hydraulic conductivity of the upper soil }\left(k_{\mathrm{sh} 1} \text { and } k_{\mathrm{sv} 1}\right) \\
\text { Effective soil moisture content of the upper soil }\left(\vartheta_{\mathrm{e}}=\vartheta_{\mathrm{s}}-\vartheta_{\mathrm{r}}\right) \\
\text { Field capacity }\left(\vartheta_{\mathrm{f}}\right) \text { of the upper soil } \\
\text { Exponent of the transmissivity law for the upper soil }\left(\alpha_{\mathrm{s}}\right) \\
\text { Exponent of the percolation law for the upper soil }\left(\alpha_{\mathrm{p}}\right) \\
\text { Vertical saturated hydraulic conductivity of the lower soil }\left(k_{\mathrm{sv} 2}\right)\end{array}$ \\
\hline Groundwater recharge & Exponent of the vertical groundwater recharge equation for the lower soil, $\alpha_{\mathrm{r}}$ \\
\hline Groundwater flow & $\begin{array}{l}\text { Horizontal saturated hydraulic conductivity of the lower soil }\left(k_{\mathrm{sh} 2}\right) \\
\text { Impermeable bedrock depth from the surface }(d) \text { and slope }\left(S_{b}\right) \\
\text { Field capacity }\left(\vartheta_{\mathrm{f}}\right) \text { of the lower soil }\end{array}$ \\
\hline Surface flow & $\begin{array}{l}\text { Surface roughness }\left(n_{\mathrm{o}}\right) \\
\text { Surface slope, } \operatorname{tang}(\beta)\end{array}$ \\
\hline Channel flow & $\begin{array}{l}\text { Roughness for the channel according to the Strahler channel order }\left(n_{\mathrm{c}}\right) \\
\text { Maximum and Minimum Channel widths }\left(W_{\max }, W_{\min }\right) \\
\text { River bed slope }\left(S_{0}\right)\end{array}$ \\
\hline Lake/reservoir routing & Routing curve \\
\hline
\end{tabular}

compared with that computed by considering only the mean value (Eq. C11).

However although it is physically based, the model still needs calibration because of the uncertainty of the information on the topography, soil characteristics and land cover. In Table $\mathrm{C} 1$ the main parameters required for each grid cell are given.

\section{C6 HYDRUS 1-D (Šimunek et al., 2008)}

HYDRUS computer code numerically solves the Richards equation (Eq. C1) for variably-saturated water flow and advection-dispersion type equations for heat and solute transport. The flow equation incorporates a sink term to account for water uptake by plant roots (Eq. C4). The flow equation may also consider dual-porosity type flow in which one fraction of the water content is mobile and another fraction immobile, or dual-permeability type flow involving two mobile regions, one representing the matrix and one the macropores. The heat transport equation considers transport due to conduction and convection with flowing water. Coupled water, vapour and energy transport can be considered as well. The solute transport equations consider advectivedispersive transport in the liquid phase, as well as diffusion in the gaseous phase. The transport equations also include provisions for nonlinear nonequilibrium reactions between the solid and liquid phases, linear equilibrium reactions between the liquid and gaseous phases, zero-order production, and two first-order degradation reactions: one which is independent of other solutes, and one which provides the coupling between solutes involved in sequential first-order decay reactions. Physical nonequilibrium solute transport can be accounted for by assuming a two-region, dual-porosity type formulation which partitions the liquid phase into separate mobile and immobile regions.

The program may be used to analyse water and solute movement in unsaturated, partially saturated, or fully saturated porous media. The flow region may be composed of nonuniform soils. Flow and transport can occur in the vertical, horizontal, or a generally inclined direction. The water flow part of the model can deal with prescribed head and flux boundaries, boundaries controlled by atmospheric 
conditions, as well as free drainage boundary conditions. The governing flow and transport equations are solved numerically using Galerkin-type linear finite element schemes.

HYDRUS-1-D also includes a parameter optimization algorithm for inverse estimation of soil hydraulic and/or solute transport and reaction parameters from measured transient or steady-state flow and/or transport data. Inverse methods are typically based upon the minimization of a suitable objective function, which expresses the discrepancy between the observed values and the predicted system response. Soil hydraulic properties for this purpose are assumed to be described by an analytical model with unknown parameter values. Initial estimates of the optimized system parameters are iteratively improved during the minimization process until a desired degree of precision is obtained

Minimization of the objective function is accomplished by using the Levenberg-Marquardt nonlinear minimization method that combines the Newton and steepest descend methods, and generates confidence intervals for the optimized parameters.

Acknowledgements. The work was partially funded by the Italian Ministry of Education and Research under the project "CUBIST Relations between hydrological processes, climate, and physical attributes of the landscape at the regional and basin scales" (Grant 2007HBTS85).

Edited by: P. Claps

\section{References}

Aarts, E. H. L. and Korst, J.: Simulated Annealing and Boltzmann Machine, Wiley \& Sons, Chichester, England, 1989.

Arangino, F., Aru, A., Baldacchini, P., and Vacca, S.: I suoli delle aree irrigabili della Sardegna, in: Regione Autonoma della Sardegna, Piano Generale delle Acque Cagliari, 1986.

Arya, L. M.: Wind and hot-air methods, in: Methods of soil analysis, Part 4, Physical methods, SSSA Book Ser. 5, Madison, WI, 916-926, 2002.

Arya, L. M. and Paris, J. F.: A physic empirical model to predict the soil moisture characteristic from particle-size distribution and bulk density data, Soil Sci. Soc. Am. J., 45, 1023-1030, 1981.

Aubertin, G. M.: Nature and extent of macropores on forest soils and their influence on subsurface water movement, USDA, Forest Serv. Res. Pap. NE-192, USDA, Washington, DC, 1971.

Bartoli, F., Regalado, C., Basile, A., Buurman, P., and Coppola, A.: Physical properties in European volcanic soils: a synthesis, in: Soils of Volcanic Regions of Europe, edited by: Arnalds, Ó., Bartoli, F., Buurman, P., Oskarsson, H., Stoops, G., and GarciaRodeja, E., ISBN: 10:3-540-48710-7, 515-537, 2007.

Basile, A. and D’Urso, G.: Experimental corrections of simplified methods for predicting water retention curves in clay-loamy soils from particle-size determination, Soil Technol., 10, 261$272,1997$.
Basile, A., De Mascellis, R., and Terribile, F.: Il suolo e la protezione degli acquiferi: studio pedologico e idrologico dei suoli della piana del F. Sarno (Campania), Quaderni di Geologia Applicata, 1, 251-261, 1999.

Bastiaanssen, W. G. M., Allen, R. G., Droogers, P., D’Urso, G., and Steduto, P.: Twenty-five years modeling irrigated and drained soils: State of the art, Agr. Water Manage., 92, 111-125, 2007.

Beven, K.: Changing ideas in hydrology - The case of physicallybased models, J. Hydrol., 105, 157-172, 1989.

Bilonick, R. A.: Monthly hydrogen ion deposition maps for the northeastern U.S. from July 1982 to September 1984, Atmos. Environ., 22, 1909-1924, 1988.

Bittelli, M. and Flury, M.: Errors in water retention curves determined with pressure plates, Soil Sci. Soc. Am. J., 73, 1453-1460, 2009.

Bolt, G. H.: Soil Chemistry, B, Physico-Chemical Models, Elsevier, 527 pp., 1982.

Bonfante, A., Basile, A., Acutis, M., De Mascellis, R., Manna, P., Perego, A., and Terribile, F.: SWAP, CropSyst and MACRO comparison in two contrasting soils cropped with maize in Northern Italy, Agr. Water Manage., 97, 1051-1062, 2010.

Bouma, J.: Soil morphology and preferential flow along macropores, Agr. Water Manage., 3, 235-250, 1981.

Bouma, J.: Using soil survey data for quantitative land evaluation, Adv. Soil Sci., 9, 177-213, 1989.

Bouma, J.: Hydropedology as a powerful tool for environmental policy research, Geoderma, 131, 275-286, 2006.

Bouma, J., Fox, C. A., and Miedema, R.: Micromorphology of Hydromorphic soils, Applications for soil genesis and land evaluation, in: Douglas, LA Soil Micromorphology: a basic and applied science, Development in Soil Science, 19, Elsevier Amsterdam, 257-278, 1990.

Bouma, J., de Vos, J. A., Sonneveld, M. P. W., Heuvelink, G. B. M., and Stoorvogel, J. J.: The role of scientists in multiscale land use analysis: lessons learned from Dutch communities of practice, Adv. Agron., 97, 175-237, 2008.

Campbell, G.: Transport Models for Soil-Plant Systems, Elsevier, Amsterdam, The Netherlands, 1985.

Campbell, G. S. and Diaz, R.: Simplified Soil-Water Balance Models to Predict Crop Transpiration, ICRISAT, Patancheru, India, 1988.

Carré, F., McBratney, A. B., Mayr, T., and Montanarella, L.: Digital soil assessments: Beyond DSM, Geoderma, 142, 69-79, 2007.

Ciarapica, L. and Todini, E.: TOPKAPI: a model for the representation of the rainfall-runoff process at different scales, Hydrol. Process., 16, 207-229, 2002.

Commission of the European Communities: Towards a Thematic Strategy for Soil Protection, 179 final, Brussels, 2002.

Coppola, A., Basile, A., Comegna, A., and Lamaddalena, N.: Monte Carlo analysis of field water flow comparing uni- and bimodal effective hydraulic parameters for structured soil, J. Contam. Hydrol., 104, 153-165, 2009.

D’Urso, G. and Basile, A.: Physico-empirical approach for mapping soil hydraulic behaviour, Hydrol. Earth Syst. Sci., 1, 915923, doi:10.5194/hess-1-915-1997, 1997.

D'Urso, G. and Minacapilli, M.: A semi-empirical approach for surface soil water content estimation from radar data without apriori information on surface roughness, J. Hydrol., 321, 297310, 2006. 
Dane, J. H. and Hopmans, J. W.: Water retention and storage, in: Methods of soil analysis: Part 4-Physical methods, SSSA Book Ser. 5, edited by: Dane, J. K. and Topp, G. C., SSSA, Madison, WI, USA, 671-720, 2002.

de Bruin, S. and Stein, A.: Soil-landscape modelling using fuzzy c-means clustering of attribute data derived from a Digital Elevation Model (DEM), Geoderma, 83, 17-33, 1998.

De Cesare, L., Myers, D. E., and Posa, D.; Estimating and modelling space-time correlation structures, Stat. Probab. Lett., 51, 9-14, 2001a.

De Cesare, L., Myers, D. E., and Posa, D.: Product-sum covariance for space-time modelling: an environmental application, Environmetrics, 12, 11-23, 2001b.

De la Rosa, D., Mayol, F., Diaz-Pereira, E., Fernandez, M., and de la Rosa Jr., D.: A land evaluation decision support system (MicroLEIS DSS) for agricultural soil protection with special reference to the Mediterranean region, Environ. Modell. Softw., 19, 929-942, 2004.

Dent, D. and Young, A.: Soil survey and Land evaluation, George Allen \& Unwin, London, UK, 278 pp., 1981.

Dobos, E., Carré, F., Hengl, T., Reuter, H. I., and Tóth, G.: Digital Soil Mapping as a support to production of functional maps, EUR 22123 EN, Office for Official Publications of the European Communities, Luxemburg, 68 pp., 2006.

Döll, P., Kaspar, F., and Lehner, B.: A global hydrological model for deriving water availability indicators: model tuning and validation, J. Hydrol., 270, 105-134, 2003.

Dokuchaev, V. V.: Russian Chernozems (Russkii Chernozem), Israel Prog. Sci. Trans. Jerusalem, 1967, Transl. from Russian by: Kaner, N., available from U.S. Dept. of Commerce, Springfield, Va, 1883.

Dunne, T.: Field studies of hillslope flow processes, in: Hillslope Hydrology, edited by: Kirkby, M. J., Wiley, New York, 227-293, 1978.

Durand, N., Monger, H. C., and Canti, M. G.: Calcium carbonate features, in: Interpretation of Micromorphological Features of Soils and Regoliths, edited by: Stoops, G., Marcelino, V., and Mees, F., Elsevier, Amsterdam, 149-194, 2010.

FAO: A Framework for Land Evaluation, Soil Bull., 32, FAO, Rome, Italy, 1976.

FAO: Guidelines for Soil Profile Description, 4, FAO, Rome, Italy, 2006

Feddes, R. A., Kowalik, P. J., and Zaradny, H.: Simulation of field water use and crop yield, Simulation Monographs, Pudoc, Wageningen, 195 pp., 1978.

Grayson, R. and Blöschl, G.: Spatial Patterns in Catchment Hydrology: Observations and Modelling, Cambridge University Press, 404 pp., 2000.

Grunwald, S.: Multi-criteria characterization of recent digital soil mapping and modeling approaches, Geoderma, 152, 195-207, 2009

Herrero, J., Robinson, D. A., and Nogues, J.: A regional soil survey approach for upgrading from flood to sprinkler irrigation in a semi-arid environment, Agr. Water Manage., 93, 145-152, 2007.

Heuvelink, G. B. M. and Pebesma, E. J.: Spatial aggregation and soil process modeling, Geoderma, 89, 47-65, 1999.

Hseu, Z. Y. and Chen, Z. S.: Saturation, reduction and redox morphology of seasonally flooded Alfisols in Taiwan, Soi Sci. Soc. Am. J., 60, 941-949, 1996.
Jenny, H.: Factors of soil formation, McGraw-Hill, New York, USA, 1941.

Jhorar, R. K., van Dam, J. C., Bastiaanssen, W. G. M., and Feddes, R. A.: Calibration of effective soil hydraulic parameters of heterogeneous soil profiles, J. Hydrol., 285, 233-247, 2004.

Jones, A., Montanarella, L., and Jones, R.: Soil atlas of Europe, European Soil Bureau Network, European Commission, Ispra, 128 pp., 2005.

Kuhn, P., Aguilar, J., and Miedema, R.: Textural features and related horizons, in: Interpretation of Micromorphological Features of Soils and Regoliths, edited by: Stoops, G., Marcelino, V., and Mees, F., Elsevier, Amsterdam, 217-250, 2010.

Lambert, J. J., Daroussin, J., Eimberck, M., Le Bas, C., Jamagne, M., King, D., and Montanarella, L.: Soil Geographical Database for Eurasia \& The Mediterranean: Instructions Guide for Elaboration at scale 1:1,000,000, Version 4.0, Office for Official Publications of the European Communities, Luxembourg, 64 pp., 2003.

Lark, R. M. and Bishop, T. F. A.: Cokriging particle size fractions of the soil, Eur. J. Soil Sci., 58, 763-774, 2007.

Lin, H.: Earth's Critical Zone and hydropedology: concepts, characteristics, and advances, Hydrol. Earth Syst. Sci., 14, 25-45, doi:10.5194/hess-14-25-2010, 2010.

Lin, H.: Hydropedology: Towards new insights into interactive pedologic and hydrologic processes across scales, J. Hydrol., 406, 141-145, 2011.

Lin, H., Bouma, J., Pachepsky, Y., Western, A., Thompson, J., van Genuchten, R., Vogel, H. J., and Lilly, A.: Hydropedology: Synergistic integration of pedology and hydrology, Water Resour. Res., 42, W05301, doi:10.1029/2005WR004085, 2006.

Lin, H. S., McInnes, K. J., Wilding, L. P., and Hallmark, C. T.: Effects of Soil Morphology on Hydraulic Properties: I. Quantification of Soil Morphology, Soil Sci. Soc. Am. J., 63, 948-954, 1999.

Lin, H. S., Brooks, E., McDaniel, P., and Boll, J.: Hydropedology and Surface/Subsurface Runoff Processes, in: Encyclopedia of Hydrologic Sciences, edited by: Anderson, M. G. and Mcdonnell, J. J., John Wiley \& Sons, Chichester, 1-25, 2008.

Lindbo, D. L., Stolt, M. H., and Vepraskas, M. J.: Redoximorphic features, in: Interpretation of Micromorphological Features of Soils and Regoliths, edited by: Stoops, G., Marcelino, V., and Mees, F., Elsevier, Amsterdam, 129-147, 2010.

Liu, Z. and Todini, E.: Towards a comprehensive physically-based rainfall-runoff model, Hydrol. Earth Syst. Sci., 6, 859-881, doi:10.5194/hess-6-859-2002, 2002.

Liu, Z., Martina, M. L. V., and Todini, E.: Flood forecasting using a fully distributed model: application of the TOPKAPI model to the Upper Xixian Catchment, Hydrol. Earth Syst. Sci., 9, $347-$ 364, doi:10.5194/hess-9-347-2005, 2005.

Lyon, S. W., Seibert, J., Lembo, A. J., Walter, M. T., and Steenhuis, T. S.: Geostatistical investigation into the temporal evolution of spatial structure in a shallow water table, Hydrol. Earth Syst. Sci., 10, 113-125, doi:10.5194/hess-10-113-2006, 2006.

Manna, P., Basile, A., Bonfante, A., De Mascellis, R., and Terribile, F.: Comparative Land Evaluation approaches: An itinerary from FAO framework to simulation modelling, Geoderma, 150, 367378, 2009. 
Martina, M. L. V. and Entekhabi, D.: Identification of runoff generation spatial distribution using conventional hydrologic gauge time series, Water Resour. Res., 42, W08431, doi:10.1029/2005WR004783, 2006.

McBratney, A. B., Mendoça Santos, M. L., and Minasny, B.: On digital soil mapping, Geoderma, 117, 3-52, 2003.

McDonnell, J. J., Sivapalan, M., Vaché, K., Dunn, S., Grant, G., Haggerty, R., Hinz, C., Hooper, R., Kirchner, J., Roderick, M. L., Selker, J., and Weiler, M.: Moving beyond heterogeneity and process complexity: a new vision for watershed hydrology, Water Resour. Res., 43, W07301, doi:10.1029/2006WR005467, 2007.

McKenzie, N. J. and Ryan, P. J.: Spatial prediction of soil properties using environmental correlation, Geoderma, 89, 67-94, 1999.

McKenzie, N. J., Grundy, M. J., Webster, R., and Ringroase-Voase, A. J.: Guidelines for surveying soil and land resources, CSIRO Publishing, Melbourne, Australia, 557 pp., 2008.

Minasny, B., McBratney, A., and Salvador-Blanes, S.: Quantitative models for pedogenesis - A review, Geoderma, 144, 140-157, 2008.

Mualem Y.: A new model for predicting the hydraulic conductivity of unsaturated porous media, Water Resour. Res., 12, 513-522, 1976.

Munsell Color (Firm): Munsell soil color charts, Munsell Color Company, 2441 North Calvert Street, Baltimore, MD 21218, 1975.

Nanzyo, M., Shoji, S., and Dahlgren, R.: Physical characteristics of volcanic ash soils, in: Volcanic Ash Soils: Genesis, Properties and Utilization, editd by: Shoji, S., Nanzyo, M., and Dahlgren, R., Development in Soil Science, vol. 17, Elsevier, Amsterdam, 189-201, 1993.

Odeh, I. O. A., McBratney, A. B., and Chittleborough, D. J.: Further results on prediction of soil properties from terrain attributes: heterotopic cokriging and regression-kriging, Geoderma, 67, 215-226, 1995.

Oliver, M. A.: Geostatistical Applications for Precision Agriculture, Springer, London, UK, 295 pp., 2010.

Pachepsky, Y. A. and Rawls, W. R.: Development of Pedotransfer Functions in Soil Hydrology, Elsevier, New York, 2004.

Park, S. J. and Vlek, P. L. G.: Environmental correlation of threedimensional soil spatial variability: a comparison of three adaptive techniques, Geoderma, 109, 117-140, 2002.

Poch, R. M., Artieda, O., Herrero, J., and Lebedeva-Verba, M.: Gypsic features in soils and sediments, in: Interpretation of Micromorphological Features of Soils and Regoliths, edited by: Stoops, G., Marcelino, V., and Mees, F., Elsevier, Amsterdam, 195-216, 2010.

Rabenhorst, M. C., Bell, J. C., and McDaniel, P. A.: Quantifying soil hydromorphology, Soil Science Society of America Special Publication 54, SSA, Madison, Wisconsin, USA, p.258, 1998.

Rawls, W. J.: Estimating soil bulk density from particle size analysis and organic matter content, Soil Sci., 136, 48-55, 1983.

Reynolds, W., Elrick, D., Youngs, E. G., Amoozegar, A., Bootlink, H. W. G., and Bouma, J.: Laboratory methods, in: Methods of Soil Analysis, Part 4, Physical Methods, SSSA Book Ser. 5, Soil. Sci. Soc. Am., Madison, WI, 802-816, 2002.

Ritsema, C. J., van Dam, J. C., Dekker, L. W., and Oostindie, K.: A new modelling approach to simulate preferential flow and transport in water repellent porous media: model structure and validation, Aust. J. Soil Res., 43, 361-369, 2005.

Rossel, R. A. V., McBratney, A. B., and Minasny, B.: Proximal Soil Sensing, Series: Progress in Soil Science, Vol. 1, 1st Edn., 468 pp., 2010.

Rossiter, D. G.: Digital soil resource inventories: status and prospects, Soil Use Manage., 20, 296-301, 2004.

Rouse, J. W., Haas, R. H., Schell, J. A., Deering, D. W., and Harlan, J. C.: Monitoring the vernal advancement of retrogradation of natural vegetation, NASA/GSFC type II, Progress Report RSC 1978-1, Greenbelt, MD, 371 pp., 1973.

Salvador-Blanes, S., Minasny, B., and McBratney, A. B.: Modelling long-term in situ soil profile evolution: application to the genesis of soil profiles containing stone layers, Eur. J. Soil Sci., 58, 1535-1548, 2007.

Samouëlian, A. and Cornu, S.: Modelling the formation and evolution of soils, towards an initial synthesis, Geoderma, 145, 401409, 2008.

Schabenberger, O. and Pierce, F. J.: Contemporary Statistical Models for the Plant and Soil Sciences, CRC Press, Boca Raton, Florida, USA, 738 pp., 2002.

Šimunek, J., van Genuchten, M. Th., Gribb, M. M., and Hopmans, J. W.: Parameter estimation of unsaturated soil hydraulic properties from transient flow processes, Soil Till. Res., 47, 27-36, 1998.

Šimunek, J., Šejna, M., Saito, H., Sakai, M., and van Genuchten, M. Th.: The Hydrus-1D Software Package for Simulating the Movement of Water, Heat, and Multiple Solutes in Variably Saturated Media, Version 4.0, HYDRUS Software Series 3, Department of Environmental Sciences, University of California Riverside, Riverside, California, USA, 315 pp., 2008.

Snepvangers, J. J. J. C., Heuvelink, G. B. M., and Huisman, J. A.: Soil water content interpolation using spatio-temporal kriging with external drift, Geoderma, 112, 253-271, 2003.

Soil Science Society of America: Glossary of Soil Science Terms, USDA Soil Survey Manual, 2003.

Soil Survey Division Staff: Soil survey manual, Soil Conservation Service, U.S. Department of Agriculture, Handbook 18, 1993.

Stöckle, C. O., Martin, S., and Cambell, G.: A model to assess environmental impact of cropping systems, Amer. Soc. of Agr. Eng., 92-2041, 1992.

Stöckle, C. O., Donatelli, M., and Nelson, R.: CropSyst, a cropping systems simulation model, Eur. J. Agron., 18, 289-307, 2003.

Stolpe, N. B., Kuzila, M. S., and Shea, P. J.: Importance of Soil Map Detail in Predicting Pesticide Mobility in Terrace Soils, Soil Sci., 163, 394-403, 1998.

Stoops, G. and Eswaran, H.: Morphological characteristics of wet soils, in Wetland soils: Characterization, classification and utilization, IRRI, Los Banos, Philippines, 177-189, 1985.

Todini, E.: The ARNO rainfall-runoff model, J. Hydrol., 175, 339382, 1996.

Todini, E.: Hydrological catchment modelling: past, present and future, Hydrol. Earth Syst. Sci., 11, 468-482, doi:10.5194/hess11-468-2007, 2007.

Tucker, C. J. and Sellers, P. J.: Satellite remote sensing of primary production, Int. J. Remote Sens., 7, 1395-1416, 1986.

USBR - Bureau of Reclamation Manual: Vol. V, Irrigated land use, Part 2, Land classification, Bureau of Reclamation, Dept. of Interior, Denver Federal Center, Denver, Col. 80225, USA, 1951. 
USBR - Bureau of Reclamation: Irrigated Land Use, Land Classification, V, Bureau of Reclamation, Dept. of Interior, Denver Federal Center, Denver, 1981.

USDA - Soil Survey Staff: Keys to Soil Taxonomy, 11th Edn., USDA-Natural Resources Conservation Service, Washington, DC, 2010.

van Dam, J. C., Huygen, J., Wesseling, J. G., Feddes, R. A., Kabat, P., van Walsum, P., Groenendijk, P., and van Diepen, C. A.: Theory of SWAP version 2.0, Dept. of Water Resources, WAU, Wageningen, Netherlands, Rep. 71, 168 pp., 1997.

Van Genuchten, M. Th.: A closed-form equation for predicting the hydraulic conductivity of unsaturated soils, Soil Sci. Soc. Am. J., 44, 892-898, 1980.

Vepraskas, M. J.: Redoximorphic Features for Identifying Aquic Conditions, Technical Bulletin, 301, North Carolina Agricultural Research Service, Raleigh, NC, USA, p.33, 2004.

Vereecken, H., Maes, J., Feyen, J., and Darius, P.: Estimating the soil moisture retention characteristic from texture, bulk density and carbon content, Soil Sci., 148, 389-403, 1989.

Verhagen, A., Booltink, H. W. G., and Bouma, J.: Site-specific Management: Balancing Production Environmental Requirements at Farm Level, Agr. Syst., 49, 369-384, 1995.

Vischel, T., Pegram, G., Sinclair, S., and Parak, M.: Implementation of the TOPKAPI model in South Africa: Initial results from the Liebenbergsvlei catchment, Water Sa., 34, 331-342, 2008.

Wagener, T., Sivapalan, M., Troch, P., and Woods, R.: Catchment classification and hydrologic similarity, Geogr. Compass, 1, 901931, 2007

Wang, J., Rich, P. M., Price, K. P., and Kettle, W. D.: Relations between NDVI and tree productivity in the central great plains, Int. J. Remote Sens., 25, 3127-3138, 2004.

Warner, G. S. and Young, R. A.: Measurement of preferential flow beneath mature corn, in: Preferential flow, Proc. of the National Symp, 16-17 December 1991, edited by: Grish, T. J. and Shirmohammadi, A., Chicago, IL. ASAE, St. Joseph, MI, 1991.
Western, A. W., Grayson, R. B., Blöschl, G., Willgoose, G., and McMahon, T. A.: Observed spatial organisation of soil moisture and its relation to terrain indices, Water Resour. Res., 35, 797$810,1999$.

Wilson, J. P. and Gallant, J. C.: Terrain analysis. Principles and applications, John Wiley \& Sons, New York, 2000.

Wösten, J. H. M., Bannik, M. H., De Gruijter, J. J., and Bouma, J.: A procedure to identify different groups of hydraulicconductivity and moisture-retention curves for soil horizons, J. Hydrol., 86, 133-145, 1986.

Wösten, J. H. M., Lilly, A., Nemes, A., and Le Bas, C.: Using existing soil data to derive hydraulic parameters for simulation models in environmental studies and in land use planning - Final report on the European union funded project 1998, DLO Winand Staring Centre, Wageningen, The Netherlands, Rep. 156, 106 pp., 1998.

WRB - IUSS Working Group: World reference base for soil resources 2006 - A framework for international classification, correlation and communication, 2, World Soil Resources Reports No. 103, FAO, Rome, 2006.

Yaalon, D. H. and Bekowicz, S.: History of Soil Science, in: Advances in Geoecology, 29, Catena Verlag GMBH, 438 pp., 1997.

Yeh, T. C. J.: One-Dimensional Steady-State Infiltration in Heterogeneous Soils, Water Resour. Res., 25, 2149-2158, 1989.

Yong, R. N. and Warkentin, B. P.: Soil properties and behavior, Elsevier, The Netherlands, 449 pp., 1975.

Zhu, Q., Lin, H. S., Zhou, X., Doolittle, J., and Zhang, J.: Precision Soil Mapping for Landscape Hydrology and Crop Management in an Agricultural Landscape, Annual meetings of ASA-CSSASSSA, New Orleans, LA, 2007. 